\title{
A Multitracer Study of Radionuclides in Lake Zurich, Switzerland 2. Residence Times, Removal Processes, and Sediment Focusing
}

\author{
E. WIELAND 1 \\ Swiss Federal Institute of Water Resources and Water Pollution Control (EAWAG), Dübendorf, Switzerland
}

P. H. SANTSCHI

Department of Marine Sciences, Texas A \& M University, Galveston

\section{J. BEER}

Swiss Federal Institute of Water Resources and Water Pollution Control (EAWAG), Dübendorf. Switzerland

\begin{abstract}
Residence and settling times of particles and particle-reactive nuclides evaluated from in situ tracer studies can be used as diagnostic indicators of trace element pathways in lakes. Natural (e.g., ${ }^{210} \mathrm{~Pb},{ }^{7} \mathrm{Be}$, and ${ }^{10} \mathrm{Be}$ ) and artificial (i.e., Chernobyl ${ }^{137} \mathrm{Cs}$ ) radionuclide fluxes through Lake Zurich (at 50 and $130 \mathrm{~m}$ depth) from 1983 to 1987 , atmospheric fluxes of the same nuclides and fluxes of ${ }^{10} \mathrm{Be}$ during 1987 allowed the calculation of nuclide residence times as well as particle settling and transit velocities in Lake Zurich. The residence time of ${ }^{210} \mathrm{~Pb}$ in the lake is approximately 1 month and, hence, of the same order as the residence times of particles and stable $\mathrm{Pb}$. Steady state residence times for ${ }^{7} \mathrm{Be}$ were calculated as $150-170$ days, while non steady state, instantaneous removal residence times ranged from 50 to 800 days. Polonium 210 was removed from Lake Zurich with removal times of $10-26$, months indicating slow removal processes or efficient recycling in the lake water. Transit velocities of particles, calculated from the attenuation of $\mathrm{Chernobyl}^{137} \mathrm{Cs}$ fluxes at $50 \mathrm{~m}$ and $130 \mathrm{~m}$ depth during early May 1986 , were $17 \mathrm{~m} \mathrm{~d}^{-1}$, while $2-4.5 \mathrm{~m} \mathrm{~d}^{-1}$ was calculated as an effective settling velocity from the attenuation of ${ }^{7} \mathrm{Be}$ fluxes at $130 \mathrm{~m}$ depth as compared to $50 \mathrm{~m}$ depth. Model calculations reveal that the overall removal process of atmospherically deposited ${ }^{7} \mathrm{Be}$ from the water column to the sediments is mainly controlled by the adsorption/coagulation step and not by the rate of particle settling. Extra inputs of ${ }^{10} \mathrm{Be},{ }^{110} \mathrm{~Pb}$, or ${ }^{137} \mathrm{Cs}$ into the lower trap (i.e., "rebound flux"), originating from episodic lateral inputs of fine particles with a high content of ${ }^{210} \mathrm{~Pb},{ }^{10} \mathrm{Be}$, and ${ }^{137} \mathrm{Cs}$, were observed during the lake stratification period (i.e., summer). This novel observation of summertime radionuclide and sediment focusing is different from previously described wind-generated resuspension and focusing effects caused by river plumes and lake sediments during the stagnation period. Boundary and focusing effects for radionuclidebearing particles are proposed to explain observed suinmertime enhancements of longer-lived nuclide fluxes at $130 \mathrm{~m}$ depth as well as the decrease in calculated effective settling velocities.
\end{abstract}

\section{INTRODUCTION}

A major complicating factor in the study of lakes, as compared to the open ocean, is boundary effects due to the greater proximity in lakes of horizontal and vertical boundaries. Close proximity to horizontal boundaries can cause significant but varying effects on trace element cycling through river inputs at varying depths, seasonal resuspension of shallow and deep surface sediments (observed so far only during lake turnover), or boundary uptake and release mechanisms of solutes. These time-dependent processes thus complicate the interpretation of trace element and radionuclide profiles in the water column of lakes (for example, see the review by Santschi [1989]). Even though the particle flux through the water column plays an important role in the removal process of trace elements from surface water [e.g., Santschi, 1984], our knowledge of boundary effects as they affect trace element cycling in lakes is still in its infancy. The aim of the present study was to infer the importance of

\footnotetext{
1 Now at Department of Civil Engineering, Terman Engineering Center, Stanford University, Stanford, California.
}

Copyright 1991 by the American Geophysical Union.

Paper number $91 \mathrm{JC} 01766$.

0148-0227/91JC-01766\$05.00 boundary effects on radionuclide behavior in the interior of a lake. For this purpose, the time scales for nuclide scavenging and particle settling were determined, and their relationships with particle fluxes were established.

Radionuclide residence times in the lake were calculated from nuclide fluxes and standing crops (i.e., amounts normalized to surface area of lake). The tracer nuclides include the atmospherically delivered radionuclides ${ }^{7} \mathrm{Be}$ (cosmogenic origin, half-life of 53 days), ${ }^{10} \mathrm{Be}$ (cosmogenic origin, halflife $1.5 \times 10^{6}$ years), ${ }^{210} \mathrm{~Pb}$ (produced by radioactive decay of the soil-derived noble gas ${ }^{222} \mathrm{Rn}$ in the atmosphere, half-life of 22 years), and Chemobyl ${ }^{137} \mathrm{Cs}$ (half-life of 30 years) as near-ideal tracers with quantifiable input functions. In Lake Zurich, atmospheric precipitation was found to be the most prominent input term for many particle-reactive radionuclides and trace elements.

In this paper, we discuss radionuclide data presented by Schuler et al. [this issue] with respect to particle flux control of the removal rates of radionuclides. A detailed evaluation of particle settling times and velocities calculated from ${ }^{7} \mathrm{Be} /{ }^{10} \mathrm{Be},{ }^{7} \mathrm{Be} /{ }^{210} \mathrm{~Pb}$, and ${ }^{7} \mathrm{Be} /{ }^{137} \mathrm{Cs}$ ratios in settling particles and of the removal residence times of ${ }^{7} \mathrm{Be}$ using steady state and non steady state models finally provides further insight into the removal processes of radionuclides and the mechanisms of sediment and radionuclide focusing in lakes. 


\section{STUDY STIE AND METHODS}

Lake Zurich is U-shaped in cross section and has steep lateral slopes on two sides (east, west) but gentle slopes on the south and north side. The lake is divided by a dam into two basins, the Upper Lake and the Lower Lake. The mean and maximum depths of the Lower Lake are $49 \mathrm{~m}$ and $137 \mathrm{~m}$, respectively. The sediment traps were deployed at two water depths $(50 \mathrm{~m}$ and $130 \mathrm{~m})$ at the deepest part of the Lower Lake. The horizontal distance between the 50-m and the $130-\mathrm{m}$ isobaths on the north and south side is about $6 \mathrm{~km}$, but only $500 \mathrm{~m}$ along the steep lateral slopes on the east and west side. The sediment traps collected between 0.1 and several grams of settling particles within the 14 to 21 days of deployment. The freeze-dried samples were measured with gamma ray spectrometry using a high purity Ge well detector [Schuler et al., this issue]. The dry weight was corrected for contribution of dissolved salts resulting from freeze drying of supematant water. The ${ }^{10} \mathrm{Be}$ measurements were carried out at the Swiss Federal Institute of Technology (ETH)/Paul Scherrer Institute accelerator mass spectrometry (AMS) facility at Zurich. A description of analytical procedures and sample preparation is given by Schuler et al. [this issue]. A detailed description of the study site as well as a presentation of original data is given by Schuler et al. [this issue].

\section{RESULTS AND DISCUSSION}

\section{Evidence for Radioisotope Focusing}

Correlations of ${ }^{7} \mathrm{Be},{ }^{10} \mathrm{Be},{ }^{137} \mathrm{Cs}$ and ${ }^{210} \mathrm{~Pb}$ fluxes in sediment traps $A$ (at $50 \mathrm{~m}$ water depth) and $B$ (at $130 \mathrm{~m}$ water depth) are depicted in Figures $1 a-1 d$. The correlation coefficients of the linear regressions are listed in Table 1 . In all cases correlations of isotope fluxes in trap A versus trap B are significant.

Beryllium 7 fluxes in trap $A$ are higher than in the nearbottom trap $B$ due to decay of the short-lived ${ }^{7} \mathrm{Be}$ in the lake
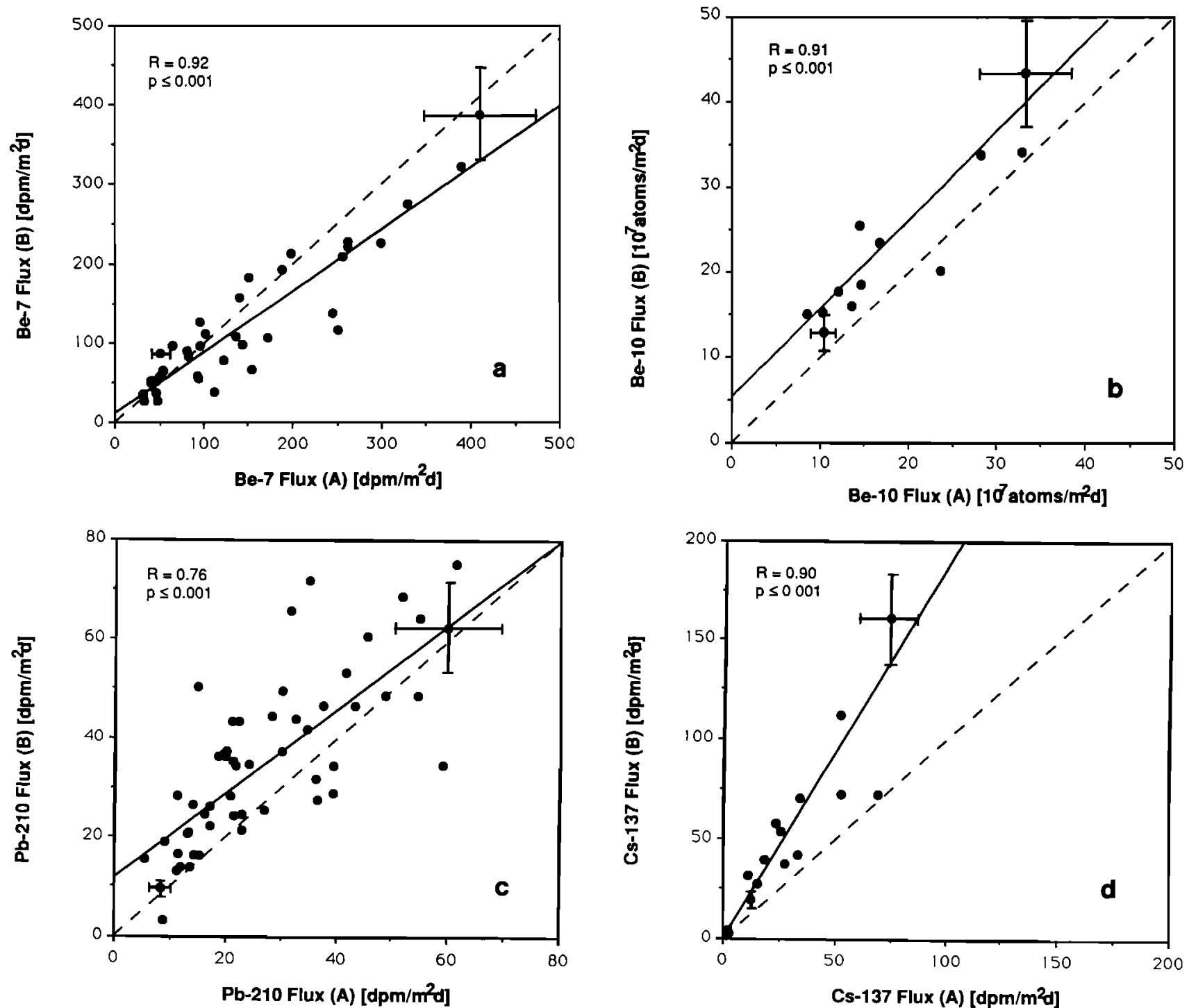

Fig. 1. Linear correlations of the fluxes of (a) ${ }^{7} \mathrm{Be},(b){ }^{10} \mathrm{Be},(c){ }^{210} \mathrm{~Pb}$, and $(d)$ Chernobyl ${ }^{137} \mathrm{Cs}$ in the near-surface (trap A at $50 \mathrm{~m}$ ) and near-bottom (trap $B$ at $130 \mathrm{~m}$ ) sediment traps. Data points represent measurements for the following periods: ${ }^{7}$ Be between 1985 and $1987,{ }^{10} \mathrm{Be}$ in $1987,{ }^{210} \mathrm{~Pb}$ between 1983 and 1987 and ${ }^{137} \mathrm{Cs}$ in 1987 . Solid lines indicate linear regression, and dashed lines correspond to $1: 1$ isotope fluxes. $R$ represents the correlation coefficient of the linear regression, and 1-p denotes the confidence level for rejecting the hypothesis that the parameters are not significantly correlated. Typical error bars are given for two data points at the extreme end of the correlation line. 
TABLE 1. Selected Correlations of Sediment Trap Fluxes (F) of Nuclides $\left({ }^{10} \mathrm{Be},{ }_{\mathrm{Be}}{ }^{210_{\mathrm{Pb}}}{ }^{137} \mathrm{Cs}\right)$ With Each Other and Particle Fluxes

\begin{tabular}{|c|c|c|c|c|c|c|}
\hline \multirow[b]{2}{*}{ Correlated Parameters } & \multicolumn{2}{|c|}{ Yearly Data } & \multicolumn{2}{|c|}{ SummerDath } & \multicolumn{2}{|c|}{ Winter Data } \\
\hline & $\mathbf{r}$ & $\mathbf{n}$ & $\mathbf{r}$ & $\mathbf{n}$ & $\mathrm{r}$ & $\mathbf{n}$ \\
\hline $\left.\mathrm{F}^{7}{ }^{7} \mathrm{Be}\right)$ STA versus $\mathrm{F}$ (particle) STA & - & - & - & - & 0.95 & $14^{a}$ \\
\hline $\left.\mathrm{F}^{7}{ }^{7} \mathrm{Be}\right)_{S T B}$ versus $\mathrm{F}$ (particle) $\mathrm{STB}$ & - & - & - & - & 0.93 & $14^{a}$ \\
\hline $\mathrm{F}\left({ }^{210} \mathrm{~Pb}\right)$ STA versus $\mathrm{F}$ (particle)STA & - & - & - & - & 0.79 & $19^{a}$ \\
\hline $\mathrm{F}\left({ }^{\left.210_{\mathrm{Pb}}\right) \text { STB }}\right.$ veraus $\mathrm{F}$ (particle)STB & - & - & - & - & 0.75 & $19^{a}$ \\
\hline $\mathbf{F}\left({ }^{137} C_{s}\right)$ STA versus $F($ particle)STA & - & - & - & - & 0.46 & 6 \\
\hline$F\left({ }^{137} \mathrm{Cs}\right)$ STB versus $F($ particle)sTB & - & - & - & - & 0.50 & 6 \\
\hline$F($ particle) STA versus $F$ (particle) STB & 0.97 & $54^{a}$ & 0.94 & $35^{a}$ & 0.96 & $19^{a}$ \\
\hline $\mathrm{F}\left({ }^{\left.10_{\mathrm{Be}}\right)}\right)_{S T A}$ versus $\mathrm{F}\left({ }^{\left.10_{\mathrm{Be}}\right)} \mathrm{STB}\right.$ & 0.91 & $12^{a}$ & 0.89 & $7^{a}$ & 0.92 & $5^{a}$ \\
\hline $\left.\mathrm{F}^{7} \mathrm{Be}\right)_{S T A}$ versus $\mathrm{F}\left({ }^{7} \mathrm{Be}\right)$ STB & 0.92 & $37^{a}$ & 0.88 & $25^{a}$ & 0.69 & $12^{b}$ \\
\hline $\left.\mathrm{F}^{210} \mathrm{~Pb}\right)_{\text {STA }}$ versus $\mathrm{F}\left(^{210} \mathrm{~Pb}\right)$ STB & 0.76 & $54^{a}$ & 0.70 & $35^{a}$ & 0.62 & $19^{b}$ \\
\hline $\left.\mathrm{F}^{\left({ }^{137} \mathrm{Cs}\right)}\right)_{\text {STA }}$ versus $\mathrm{F}\left({ }^{137} \mathrm{Cs}\right)$ STB & 0.97 & $18^{a}$ & 0.96 & $10^{a}$ & 0.96 & $8^{a}$ \\
\hline
\end{tabular}

water. The fluxes of the long-lived ${ }^{10} \mathrm{Be}, 210 \mathrm{~Pb}$, and ${ }^{137} \mathrm{Cs}$ increase in the near-bottom sediment trap.

Particle fluxes in sediment trap $A$ at $50 \mathrm{~m}$ and trap $B$ at 130 $m$ depth strongly correlate with a slope close to $1(r=0.96)$ (not shown). However, integrated particle fluxes in the nearbottom trap at $130 \mathrm{~m}$ are significantly enhanced [Schuler et al., this issue, Table 2]. As activity concentrations on particles from both traps are similar, the increase of ${ }^{10} \mathrm{Be}$ and ${ }^{210} \mathrm{~Pb}$ fluxes in the near-bottom sediment trap $B$ results mostly from an increase in the fluxes of particulate matter. In 1987, the increases in integrated fluxes were as follows: particle flux of $\sim 22 \%,{ }^{210_{\mathrm{Pb}} \text { flux of } \sim 17 \%,{ }^{10} \mathrm{Be} \text { flux of } \sim 38 \% \text { and }{ }^{137} \mathrm{Cs} \text { flux }}$ of $-65 \%$ [Schuler et al., this issue, Tables 2 and 3]. Hence we may conclude that the focusing fluxes of fine particulate material along the water-sediment interface to the deepest part of Lake Zurich are a significant supply to the overall isotope fluxes [Schuler et al., this issue, Figures $1 b$ and $1 c$, Table 2]. The enhancement in ${ }^{137} \mathrm{Cs}$ flux over that of other nuclides reveals that these particles are significantly enriched in ${ }^{137} \mathrm{Cs}$ (Figure 1d).

Correlations of isotope fluxes with each other in both sediment traps (Figures $2 a$ and $2 b$ ) and representations of isotope fluxes as a function of particle fluxes (Figures $3 a$ and 3b) allow further conclusions about the nature of removal processes and the coupling of deposition and removal processes of radionuclides in Lake Zurich. Beryllium 7 and 10 Be fluxes strongly correlate in both traps indicating similar transfer functions with respect to the nature of settling particles as well as their pathways (Figure 2a). The linear regression also reveals that in the near-surface sediment trap $A$, an additional flux of around $3 \times 10^{7}$ atoms m-2 $\mathrm{d}^{-1}{ }^{10} \mathrm{Be}$ is found when no extra ${ }^{7} \mathrm{Be}$ is supplied to the trap. This value corresponds to about $30 \%$ of the total ${ }^{10} \mathrm{Be}$ flux during wintertime (which, however, supplies considerably less than half of the annual flux). This fraction may be attributed to allochthonous material from the drainage basin, which makes up to $30 \%$ of the dry weight of settling particles in winter samples [Sigg et al., 1987]. In summer, allochthonous material represents only a few percent of the settling material and can thus be of only minor importance for the radioisotope transport. Hence, both isotopes are mainly supplied by atmospheric deposition and not by inflows from the drainage basin. The ${ }^{10} \mathrm{Be} /{ }^{7} \mathrm{Be}$ ratio in sediment trap $\mathrm{A}$ may therefore be attributed to decay of ${ }^{7} \mathrm{Be}$ and not to a significant extra input of ${ }^{10} \mathrm{Be}$ from the drainage basin. This ratio therefore represents an ideal chronometer for radionuclide and trace metal removal processes.

Correlations between ${ }^{7} \mathrm{Be}$ and ${ }^{210} \mathrm{~Pb}$ fluxes in both traps are displayed in Figure $2 b$. The scattering in the data is a consequence of differences in input variations and/or transfer processes. This effect is even more pronounced with ${ }^{137} \mathrm{Cs}$ (see the correlation coefficients in Table 1). However, correlations between ${ }^{7} \mathrm{Be}$ and ${ }^{210} \mathrm{~Pb}$ fluxes and, to a lesser extent, between ${ }^{7} \mathrm{Be}$ and ${ }^{137} \mathrm{Cs}$, are still significant at the $99 \%$ confidence level, thus allowing us to use ${ }^{7} \mathrm{Be} /{ }^{210} \mathrm{~Pb}$ and ${ }^{7} \mathrm{Be} /{ }^{137} \mathrm{Cs}$ ratios as chronometers as well.

Fluxes of ${ }^{7} \mathrm{Be}$ and ${ }^{210} \mathrm{~Pb}$ correlate with particle fluxes in the winter but not in the summer season (Figures $3 a$ and $3 b$ ). At low particle fluxes, i.e., $<2 \mathrm{~g} \mathrm{~m}^{-2} \mathrm{~d}^{-1}$, fluxes of ${ }^{7} \mathrm{Be}$ and ${ }^{210} \mathrm{~Pb}$ are controlled by sedimentation, whereas at high particle fluxes, i.e., $>2 \mathrm{~g} \mathrm{~m}^{-2} \mathrm{~d}^{-1}$ input variations may determine nuclide fluxes to the sediments (Figures $3 a$ and $3 b$, Figure 4). However, at very high atmospheric nuclide deposition rates in summer, fluxes of ${ }^{7} \mathrm{Be}$ and ${ }^{210} \mathrm{~Pb}$ from the epilimnion to the sediments are still proportional to particle fluxes (Figure 4). During wintertime, the removal of nuclides is tightly controlled by particle sedimentation rates. In summer, radionuclides are quantitatively removed by settling particles, thus allowing atmospheric input variations to control nuclide fluxes in the lake and, hence, causing the scattering in the data as depicted in Figures $3 a$ and $3 b$.

\section{Removal of ${ }^{7}$ Be: Model Calculations}

The overall removal process of radionuclides out of the water column may be interpreted in terms of a simple steady state model which includes the kinetics of the removal process 

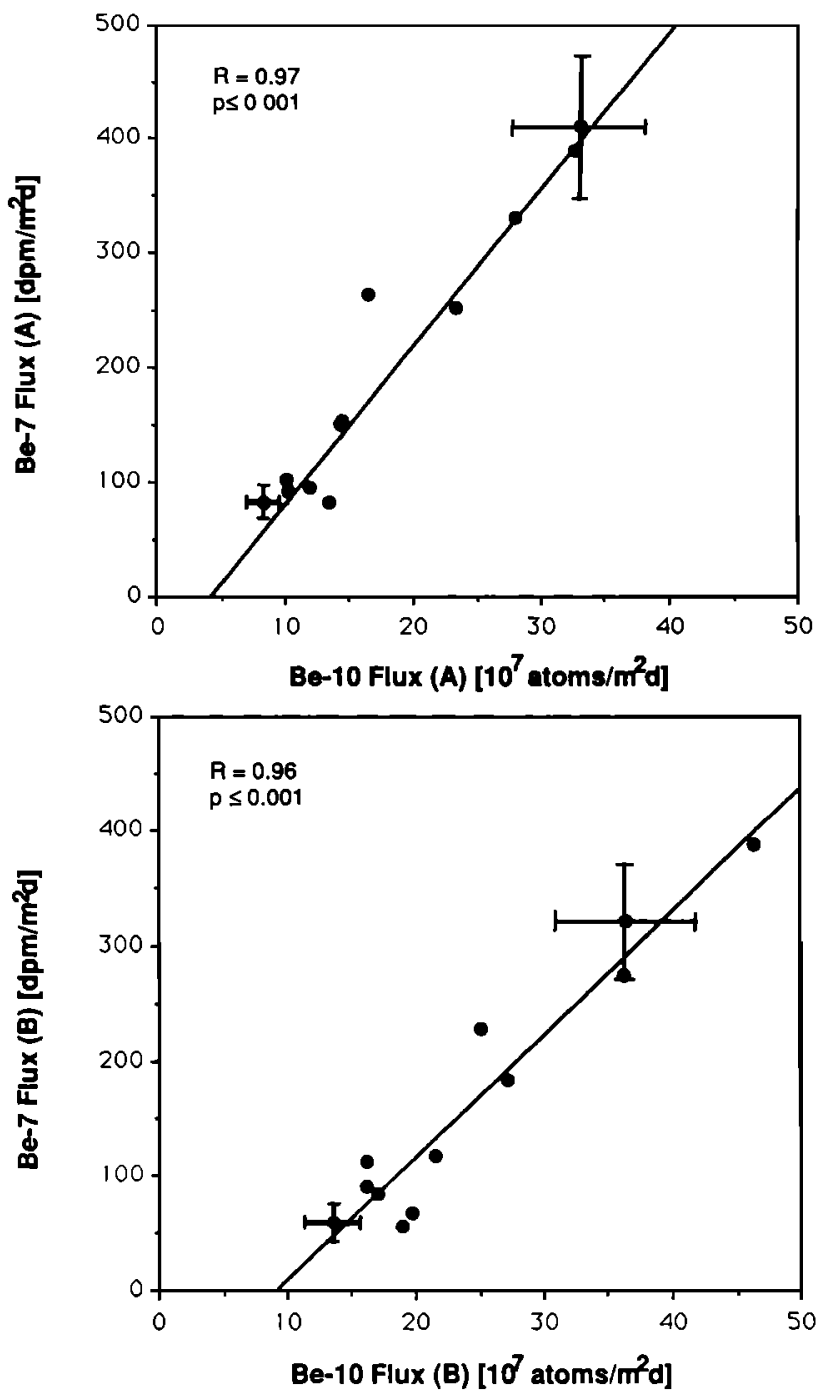

Fig. 2a. Linear correlations of ${ }^{7} \mathrm{Be}$ fluxes with fluxes of ${ }^{10} \mathrm{Be}$ deposited in the same trap (A at $50 \mathrm{~m}, B$ at $130 \mathrm{~m}$ ) (for $R$ and $p$ see Figure 1). Typical error bars are given for two data points at the extreme end of the correlation line.

as a sequence of consecutive reaction steps schematically presented in Figure S. By assuming first-order kinetics and outflow to be compensated by the river-derived, non atmospheric delivery of nuclides from the drainage basin, the atmospheric deposition of radionuclides is balanced by the radioactive decay rate plus uptake by particles [Santschi et al., 1980].

$$
P=A^{\prime}\left(\lambda_{D}+\lambda_{C}\right) \quad \text { dpm } \mathrm{cm}^{-3} \mathrm{yr}^{-1}
$$

where $P$ is the production input rate, $A$ is the activity of the nuclide in solution ( $\left.\mathrm{dpm} \mathrm{cm}^{-3}\right), \lambda_{\mathrm{D}}$ denotes the decay constant $\left(\mathrm{yr}^{-1}\right)$, and $\lambda_{C}$ is the combined rate constant of the adsorption/coagulation process $\left(\mathrm{yr}^{-1}\right)$. In a steady state system, the uptake by particles is equal to the decay rate of suspended particulate radionuclides plus the scavenging rate by settling particles

$$
\lambda_{C} A=A^{P} \cdot\left(\lambda_{D}+\lambda_{P}\right) d p m c^{-3} \mathrm{yr}^{-1}
$$

where $A^{P}$ denotes the activity of suspended particulate
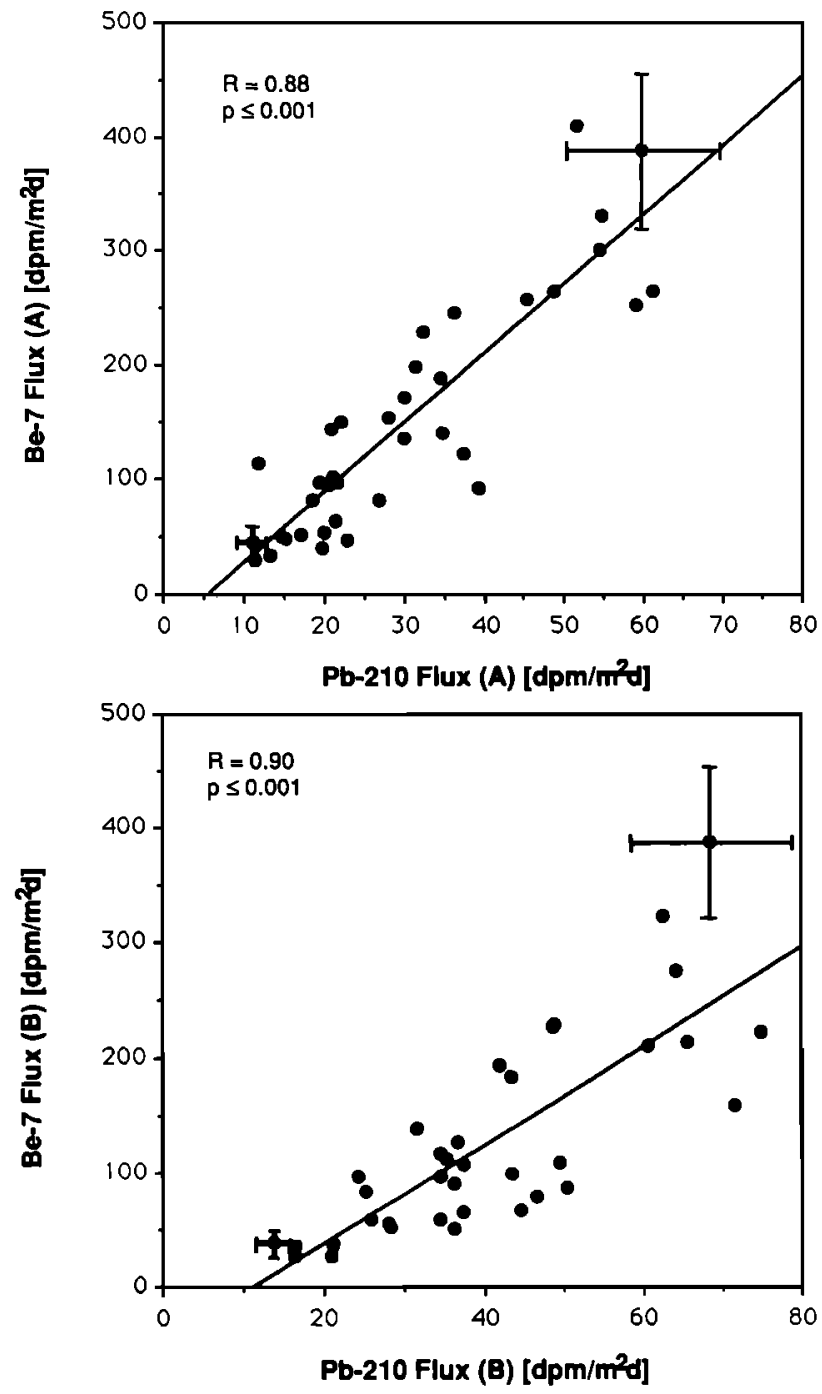

Fig. $2 b$. Same as Figure $2 a$ but for linear correlations of ${ }^{7}$ Be fluxes with fluxes of ${ }^{210} \mathrm{~Pb}$.

radionuclide ( $\mathrm{dpm} \mathrm{cm}^{-3}$ ) and $\lambda_{P}$ is the scavenging rate for particle settling $\left(\mathrm{yr}^{-1}\right)$.

During the overall removal process, the atmospheric input of a radionuclide is balanced by radioactive decay and scavenging by settling particles according to (3)

$$
P=(1 / h) \cdot \Sigma A^{\cdot}\left(\lambda_{D}+\lambda_{R}\right) \quad \text { dpm } \mathrm{cm}^{-3} \mathrm{yr}^{-1}
$$

where $\lambda_{\mathrm{R}}$ denotes the rate constant of the overall removal process of a nuclide $\left(\mathrm{yr}^{-1}\right), \mathrm{h}$ represents the mean depth $(=49 \mathrm{~m}$ in Lake Zurich), and $\Sigma A$ is the standing crop (dpm cm${ }^{-2}$ ) of the nuclide with (1/h) $\mathbf{\Sigma} \mathbf{A}=\mathbf{A}+\mathbf{A}^{\mathbf{P}}$ (see (7c)).

By combining (1) and (3), the concentration of nuclides associated with suspended particles is then given by

$$
A^{P}=A^{\cdot}\left(\lambda_{C^{-}} \lambda_{R}\right) /\left(\lambda_{D}+\lambda_{R}\right) \quad \operatorname{dpm~cm}{ }^{-3} \mathrm{yr}^{-1}
$$

Substituting $A^{P}$ in (2), the removal rate constant, $\lambda_{R}$, may be expressed as

$$
\lambda_{R}=\left(\lambda_{C} \cdot \lambda_{P}\right) /\left(\lambda_{C}+\lambda_{D}+\lambda_{P}\right) \quad y^{-1}
$$



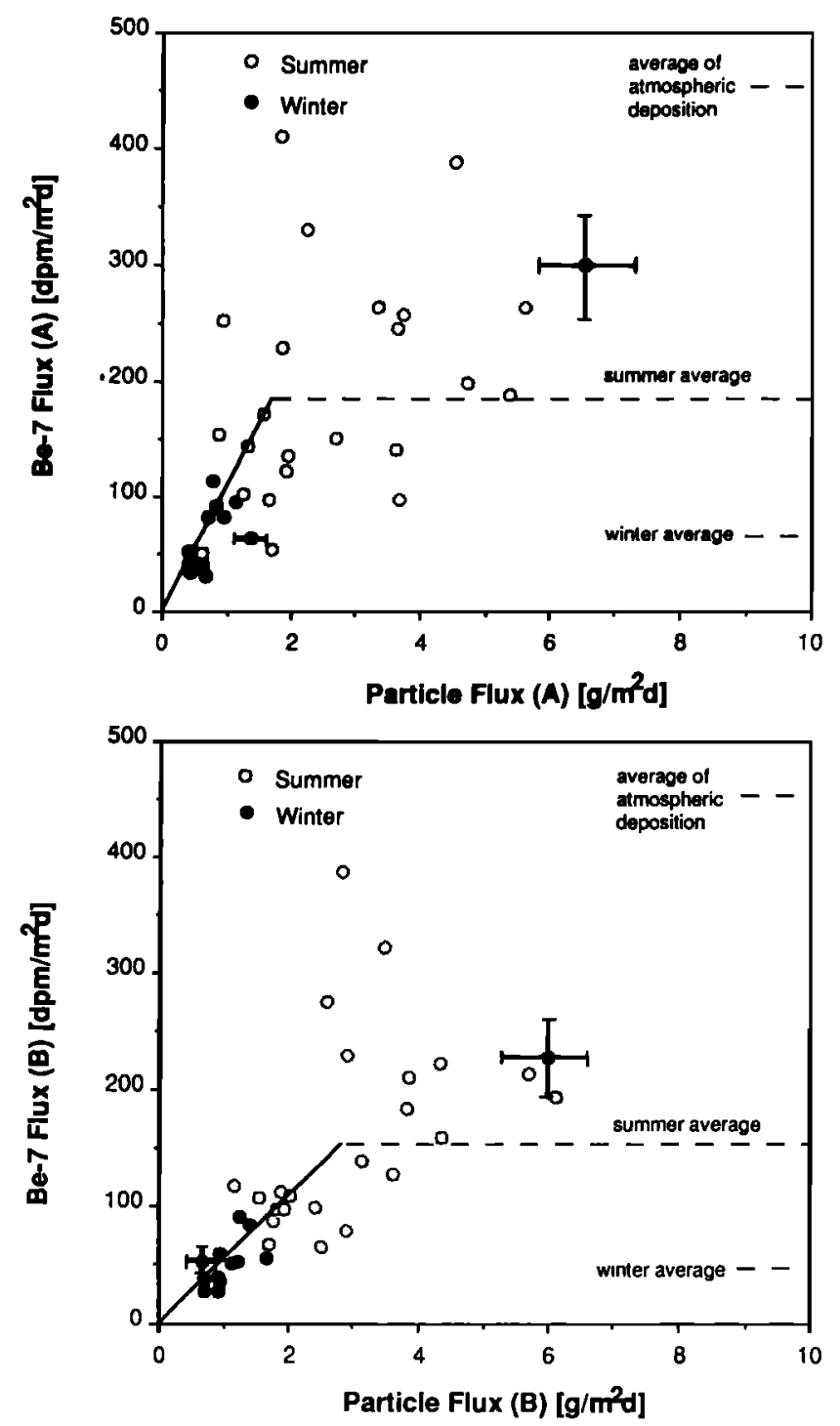

Fig. 3a. Relationship between the ${ }^{7} \mathrm{Be}$ nuclide and the particle fluxes deposited in the same trap during summer (open circles) and winter season (solid circles). Average fluxes in summer and winter as well as atmospheric deposition rates are marked. Typical error bars are given for two data points at the extreme end of the correlation line.

and, hence, the removal residence time of a nuclide, $\tau_{R}$ (which is equal to $\tau_{\mathrm{R}-\mathrm{Be}}$ for ${ }^{7} \mathrm{Be}$ ), is given by (6) [Santschi et al., 1980]

$$
\tau_{\mathbf{R}}=\tau_{\mathbf{P}}+\tau_{\mathbf{C}}+\left(\tau_{\mathbf{C}} \tau_{\mathbf{P}} / \tau_{\mathbf{D}}\right) \quad \text { years }
$$

In the following sections, we will first calculate removal residence times $\left(\tau_{R}\right)$ of ${ }^{7} \mathrm{Be}$ in Lake Zurich using steady state and non steady state models, then determine scavenging residence times for particle settling $\left(\tau_{p}\right)$, and finally evaluate residence times with respect to the adsorption/coagulation process $\left(\tau_{C}\right)$ according to (6).

\section{Calculation of Residence Times $\left(\tau_{R}\right)$ of Natural Radionuclides}

Steady state residence times. Average radionuclide residence times $\left(\tau_{R}=1 / \lambda_{R}\right)$ can be calculated from a flux balance (i.e., input $=$ radioactive decay + removal from the lake water),
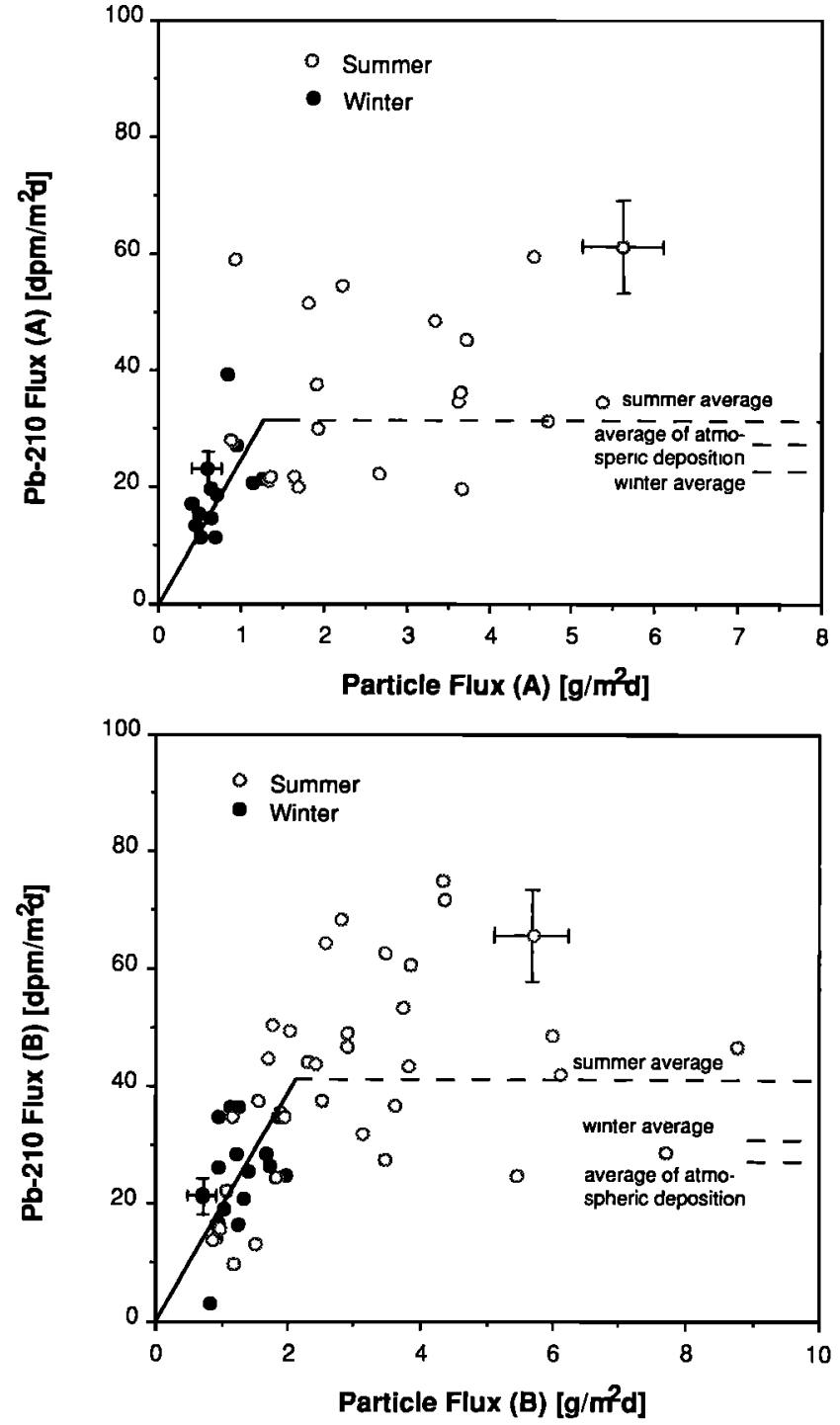

Fig. 3b. Same as Figure $3 a$ but for relationhips between the $210_{\mathrm{Pb}}$ nuclide and particle fluxes.

assuming steady state and negligible net loss to outflow during removal to sediments. Errors from violation of the latter assumption are likely to be small, since the inflow into Lake Zurich is the outflow of two higher-lying lakes (i.e., inflowoutflow $\sim 0$ ); however, the assumption of steady state is likely an oversimplification:

$$
\begin{array}{ll}
F_{\mathrm{atm}}=\lambda_{\mathrm{D}} \Sigma+\lambda_{\mathrm{R}} \Sigma & \text { dpm cm } \mathrm{cm}^{-2} \mathrm{yr}^{-1} \\
\mathrm{~F}_{\mathrm{R}}=\lambda_{\mathrm{R}} \Sigma & \text { dpm cm } \mathrm{cm}^{-2} \mathrm{yr}^{-1}
\end{array}
$$

with $\lambda_{D}$ and $\lambda_{R}$ as the rate constants for radioactive decay and removal, respectively $\left(\mathrm{yr}^{-1}\right)\left(\tau=1 / \lambda=\right.$ residence time). $\mathrm{F}_{\mathrm{atm}}$ and $F_{R}$ denote the atmospheric and removal fluxes: the latter is taken as the flux measured by sediment trap $A$ at $50 \mathrm{~m}$ depth (dpm $\mathrm{cm}^{-2} \mathrm{yr}^{-1}$ ), which is close to the mean depth of the lake. Assuming lateral homogeneity, the standing crop, $\Sigma$, of longer-lived radionuclides delivered from the atmosphere (for example, for ${ }^{7} \mathrm{Be},{ }^{210} \mathrm{~Pb}$ ) is given by the total activity integrated over depth

$$
\Sigma=o_{0}^{h} \int\left(A+A^{P}\right) \cdot d x \quad \text { dpm cm } \text { cm }^{-2}
$$




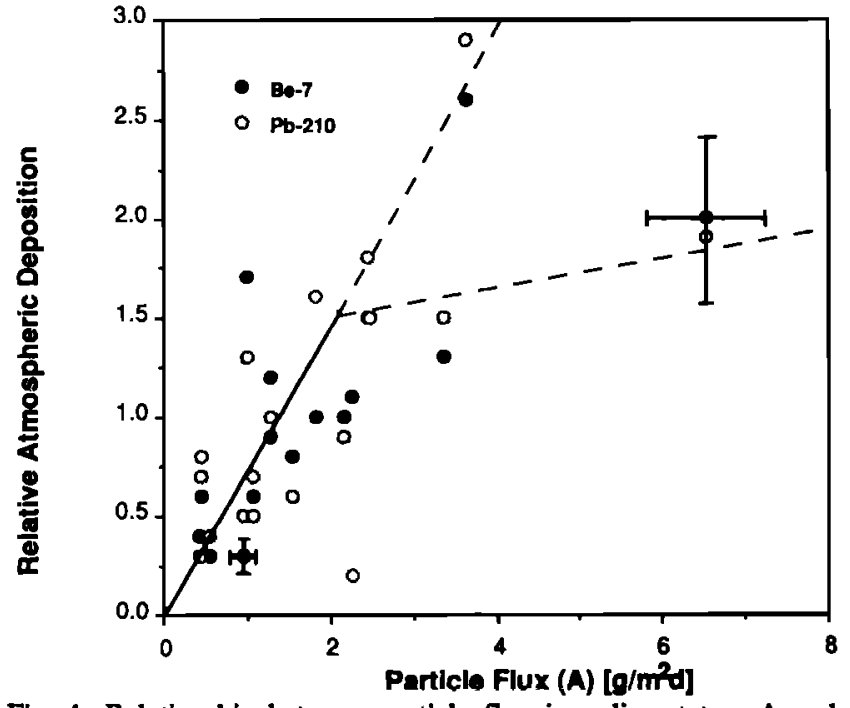

Fig. 4. Relationship between particle flux in sediment trap $A$ and relative atmospheric deposition of ${ }^{7} \mathrm{Be}$ and ${ }^{210} \mathrm{~Pb}$. Relative atmospheric deposition was calculated by dividing momentary flux during each time interval by the mean annual flux of the radionuclide. Typical error bars are given for two data points at the extreme end of the correlation line.

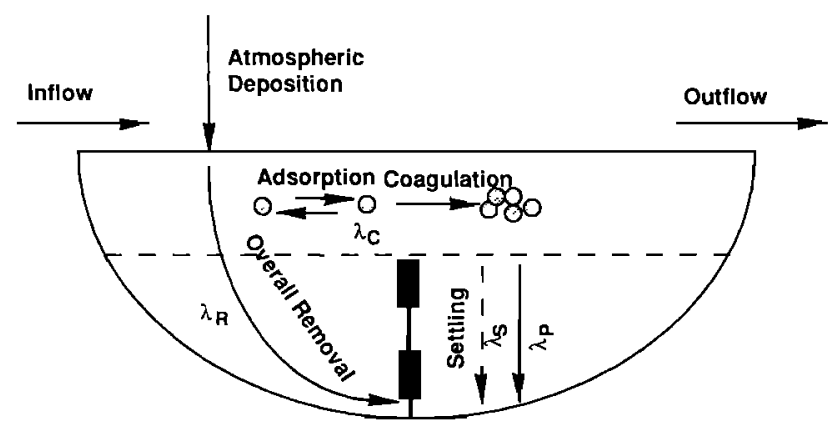

Fig. 5 Removal of ${ }^{7} \mathrm{Be}$ from Lake Zurich. The main source is atmospheric deposition. The overall removal process with residence time, $\tau_{R}$ may be separated into two consecutive processes: adsorption/coagulation with residence time $\tau_{C}$ and particle settling with residence time $\tau_{\mathrm{p}}$. Particle settling is dominated by "boundary" resuspension $\left(v_{p}=2.3 \mathrm{~m} \mathrm{~d}^{-1}, \tau_{p}=21\right.$ days), rather than by fast settling of large particles $\left(v_{P}=17 \mathrm{~m} \mathrm{~d}^{-1}, \tau_{S}=2.9\right.$ days $)$.

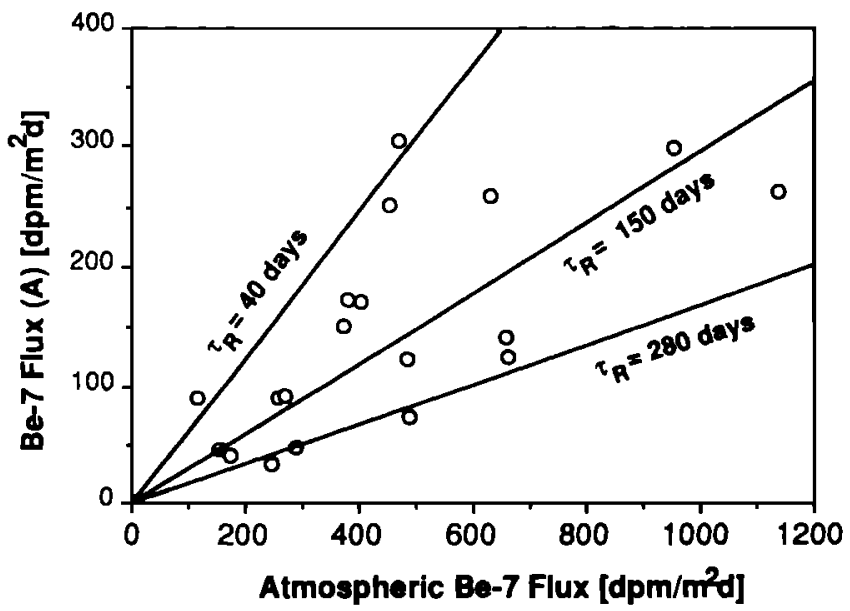

Fig. 6 Correlation of atmospheric ${ }^{7} \mathrm{Be}$ fluxes with the ${ }^{7} \mathrm{Be}$ fluxes in the near-surface sediment trap A. Solid lines represent expected flux correlations for steady state removal residence times as indicated. with $A$ and $A^{P}$ as the activities in solution and on particles, respectively ( $\mathrm{dpm} \mathrm{cm}^{-3}$ ) and $\mathrm{h}$ as the mean depth (meters).

Standing crops of the observed radionuclides are given by Schuler et al. [this issue]. Residence times $\left(\tau_{\mathbf{R}}\right)$ with respect to removal to the sediments (denoted hereafter as "removal residence times") can be calculated as $\tau_{R}=1 / \lambda_{R}$ either from (7a) or from (7b). Substitution of standing crop, $\Sigma$, in (7a) by (7b) gives the following expression for the removal residence time, $\tau_{R}$, of ${ }^{7} \mathrm{Be}$ :

$$
\tau_{R-B e}=\tau_{D}\left(F_{\text {atm }}-F_{R}\right) / F_{R}=\tau_{D}\left(F_{a t m} / F_{R}-1\right) \text { years }
$$

with $\tau_{D}=77$ days for ${ }^{7} \mathrm{Be}$. The flux ratios of $\mathrm{F}_{\mathrm{atm}} / \mathrm{F}_{\mathrm{R}}$ can be calculated for each time interval [Schuler et al,, this issue, Tables 1 and 2]. In Figure 6, atmospheric fluxes of ${ }^{7} \mathrm{Be}$ and corresponding fluxes in sediment trap A $(50 \mathrm{~m})$ are compared. Solid lines indicate expected transfer fluxes between atmosphere and sediment trap $A$ for various removal residence times in the epilimnion. Steady state removal residence times listed in Table 2 range from 23 to $\mathbf{3 3 0}$ days with an average of $176 \pm 62$ between 1983 and 1987 . Summer and winter averages are of the same order indicating no seasonal trend.

For ${ }^{210} \mathrm{~Pb}$, since $\mathrm{F}_{\mathrm{atm}}-\mathrm{F}_{\mathrm{R}}, \lambda_{\mathrm{R}-\mathrm{Pb}}$ had to be calculated from the less precisely determined values of standing crop, $\Sigma$ (from $(7 b)$ ), as follows:

$$
\tau_{\mathbf{R}-\mathrm{Pb}}=\Sigma / \mathbf{F}_{\mathbf{R}(\mathrm{A})} \quad \text { years }
$$

Average removal residence times of ${ }^{210} \mathrm{~Pb}\left(\tau_{R}=1 / \lambda_{R}\right)$, calculated as described above from known nuclide output functions and standing crops are presented in Table 2. Average values of $\tau_{R}$ for ${ }^{210} \mathrm{~Pb}$ range from 20 to 65 days with a typical removal residence time of about $\mathbf{4 0}$ days. Typical removal residence times of ${ }^{210} \mathrm{~Pb}$ reported for other lakes are: 80 days [Schell, 1974] and 72-114 days [Barnes et al., 1979] for Lake Washington, 240 days for Lake Kinneret [Stiller and Imboden, 1986], 90 days for Lake Huron [Durham and Joshi, 1980], and 37 days for Crystal Lake [Talbot and Andren, 1984].

The removal residence time of ${ }^{210} \mathrm{Po}\left(\lambda_{\mathrm{R}-\mathrm{Po}}\right)$ can be estimated from the average $210 \mathrm{Po} /{ }^{210} \mathrm{~Pb}$ activity ratio of the sinking particles and in the water, and from the production rates, as follows:

$$
\begin{aligned}
& \mathrm{F}_{\mathrm{atm}-\mathrm{Po}}+\left[^{210} \mathrm{~Pb}\right] \lambda_{\mathrm{D}-\mathrm{Po}} \cdot \mathrm{h}=\left[^{210} \mathrm{Po} \cdot\left(\lambda_{\mathrm{D}-\mathrm{Po}}+\lambda_{\mathrm{R}-\mathrm{Po}_{0}}\right) \cdot \mathrm{h}\right. \\
& \text { dpm } \text { cm }^{-2} \text { yr }^{-1}
\end{aligned}
$$

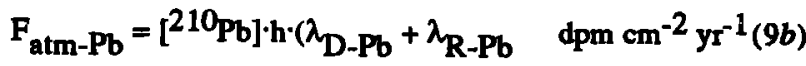

with $h$ as the mean depth $(=49 \mathrm{~m})$, and the decay constants $\lambda_{\mathrm{D}-\mathrm{Po}}=1.83 \mathrm{yr}^{-1}, \mathrm{~F}_{\mathrm{atm}-\mathrm{Po}} / \mathrm{F}_{\mathrm{atm}-\mathrm{Pb}} \leq 0.1$, and $\lambda_{\mathrm{D}-\mathrm{Pb}}=3.15$ $\times 10^{-2} \mathrm{yr}^{-1}$. The removal rate constant of ${ }^{210} \mathrm{~Pb}\left(=1 / \tau_{\mathrm{R}-\mathrm{Pb}}\right)$ is denoted by $\lambda_{\mathrm{R}-\mathrm{Pb}}$, and square brackets signify average activity of the nuclides in water ( $\$ \mathrm{pm} \mathrm{cm}^{-3}$ ).

Removal fluxes of ${ }^{210}$ Po and ${ }^{210} \mathrm{~Pb}$ are given by

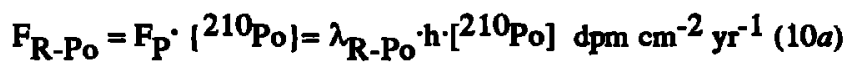

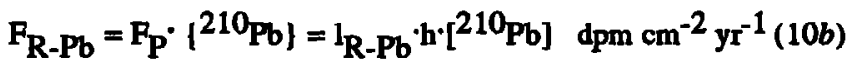


TABLE 2. Steady State Residence Times of ${ }^{7} \mathrm{Be}$ and ${ }^{210_{\mathrm{Pb}}}$ in Lake Zurich

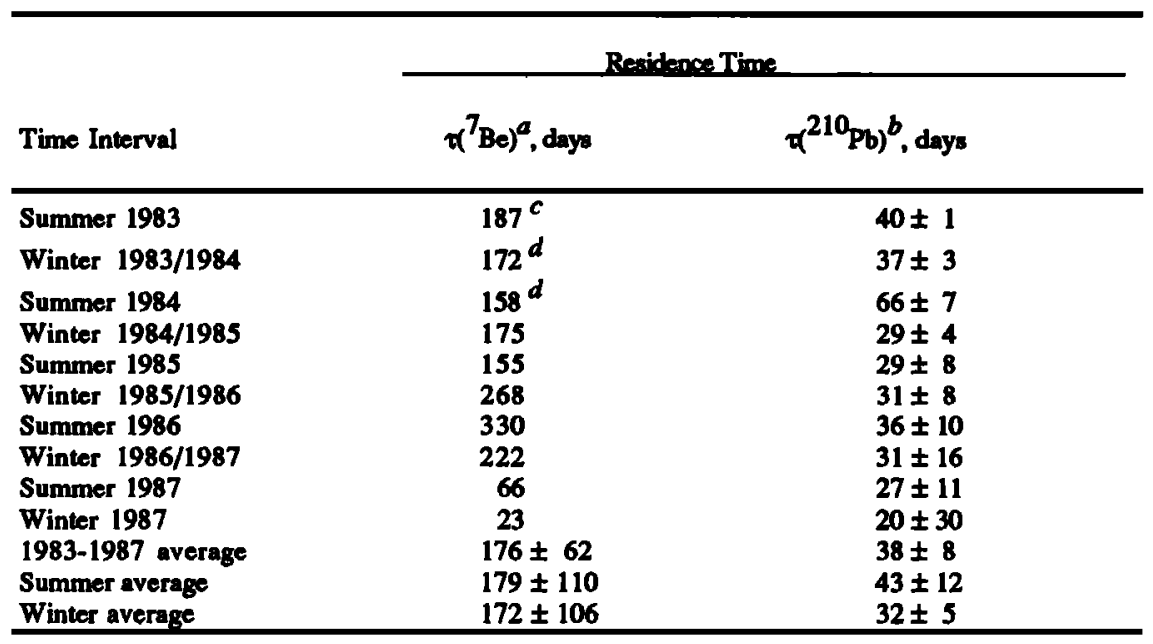

$a_{\tau}\left({ }^{7} \mathrm{Be}\right)=\tau_{\mathrm{D}}\left(\mathrm{F}_{\text {atm }}-\mathrm{F}_{\text {trap }}(\mathrm{A})\right) / \mathrm{F}_{\text {trap }}(\mathrm{A})$.

$b_{\tau}\left({ }^{210} \mathrm{~Pb}\right)=$ standing crop/ $/ 10 \mathrm{~Pb}$ trap flux.

$c$ Calculated with average summer input.

$d$ Calculated from flux attenuation of ${ }^{7} \mathrm{Be}$.

Curly braces denote average nuclide activity on particles (dpm $\mathrm{g}^{-1}$ ), square brackets average nuclide activity in the water, and $F_{P}$ the particle flux $\left(\mathrm{g} \mathrm{cm}^{-2} \mathrm{yr}^{-1}\right)$.

The ratio of respective removal residence time, $\tau_{R}$, is given by $(10 a)$ and $(10 b)$ :

$\tau_{\mathrm{R}-\mathrm{Po}} / \tau_{\mathrm{R}-\mathrm{Pb}}=\left(\left(^{\left.210_{\mathrm{Pb}}\right\}} /\left\{^{\left.\left.210_{\mathrm{Po}}\right]\right) \cdot\left(\left[{ }^{210} \mathrm{Po}\right] /\left[{ }^{210} \mathrm{~Pb}\right]\right)}\right.\right.\right.$

With $\left.\left.\right|^{210} \mathrm{~Pb}\right\} /\left\{^{210} \mathrm{Po}\right] \approx 1.5$ to 3 and $\left[{ }^{210} \mathrm{Po}\right] /\left[^{210} \mathrm{~Pb}\right] \approx 5$ to 10 [Schuler et al., this issue, Table 4], one can calculate values of $\tau_{\mathrm{R}-\mathrm{Po}} / \tau_{\mathrm{R}-\mathrm{Pb}}$ of 7.5 to 20 . Since $\tau_{\mathrm{R}-\mathrm{Pb}}$ is about 40 days, $\tau_{\mathrm{R}}$ Po ranges from 300 to 800 days. These longer time scales indicate a less efficient net scavenging of ${ }^{210}$ Po than of $210 \mathrm{~Pb}$. Significantly longer residence times for ${ }^{210} \mathrm{Po}$ than for ${ }^{210} \mathrm{~Pb}$ were also reported by Benoit and Hemond [1990] for Bickford Pond.

Since the residence time of ${ }^{210} \mathrm{~Pb}$ is only about 1 month and, hence, of the same order as the residence times of particles and $\mathrm{Pb}$ [Sigg et al., 1987], all of it should be retained in the lake sediments (water residence time is $\mathbf{1 . 2}$ years). Because of the longer residence time of ${ }^{7} \mathrm{Be}$ in the lake (176 \pm 62 days; see Table 2), a significant fraction of ${ }^{7} \mathrm{Be}$ decays in the water and therefore will be missing in the surface sediments. Some fraction could also be washed out of the lake, if inflow minus outflow is not zero for ${ }^{7} \mathrm{Be}$. Indeed, Wan et al. [1987] and Dominik et al. [1989] have reported inventories in sediments of Swiss lakes which are only $10-70 \%$ of atmospheric inputs of ${ }^{7}$ Be. Our average values measured in the sediment traps $A$ and B [Schuler et al., this issue, Table 1 and 2] range from 19\% to $54 \%$ of the atmospheric input.

An average residence time of ${ }^{7} \mathrm{Be}, \tau_{\mathrm{R}}$, of 176 days is consistent with the few values of residence times for ${ }^{7} \mathrm{~B} e$ measured in lakes, which are reported in the literature, if they are corrected for their different ratios of $F_{p} / h$ (= particle flux to mean lake depth). Removal rates, $\lambda_{R}\left(=1 / \tau_{R}\right)$ are proportional to $F_{p} / h$ for a one-box model situation at steady state [Santschi,
1984]. In Lake Geneva [Dominik et al., 1989] and Lake Greifen [Wan et al., 1987], $\lambda_{\mathrm{R}}$ for ${ }^{7} \mathrm{Be}$ are $2.5 \times 10^{-3}$ and $2.6 \times 10^{-2}$ $\mathrm{d}^{-1}$, and $\mathrm{F}_{\mathrm{p}} / \mathrm{h}$ are $2.2 \times 10^{-2}$ and $0.2 \mathrm{~g} \mathrm{~m}^{-3} \mathrm{~d}^{-1}$, respectively. Based on these values and a value for $F_{p} / h$ of $4.9 \times 10^{-2} \mathrm{~g} \mathrm{~m}^{-3}$ $\mathrm{d}^{-1}$ for Lake Zurich, we would expect a removal residence time for ${ }^{7} \mathrm{Be}$ in Lake Zurich, $\tau_{R}$, of 160 to 180 days, which is in agreement with our steady state value calculated from measured flux data.

Even though particle fluxes through the water column are a factor of 3-6 times higher in the summer months than during the winter [Schuler et al., this issue, Table 2], average ${ }^{7} \mathrm{Be}$ and $210 \mathrm{~Pb}$ nuclide residence times generally vary only by at most a factor of 2 between seasons (Table 2). The more efficient removal in winter than expected from particle flux ratios indicates lower particle scavenging efficiency for radionuclides during the summer, likely due to the lower affinity of $\mathrm{Be}$ and $\mathrm{Pb}$ for dominant $\mathrm{CaCO}_{3}$ surfaces.

Non steady state residence time of ${ }^{7} \mathrm{Be}$. The strong seasonal variations of particle fluxes, atmospheric inputs, and radionuclide fluxes [see Schuler et al., this issue] likely caused short- term fluctuations in the mean residence time of ${ }^{7} \mathrm{Be}$ in the lake. In order to evaluate if particle flux is controlling removal rates of ${ }^{7} \mathrm{Be}$, a non steady state model was applied to the sediment trap data of ${ }^{7} \mathrm{Be}$ for time periods shorter than 1 year [Dominik et al., 1989]. The overall removal residence time, $\tau_{R}\left(=\tau_{R-B e}\right.$ for $\left.{ }^{7} \mathrm{Be}\right)$, can be calculated for each measured time interval, as follows:

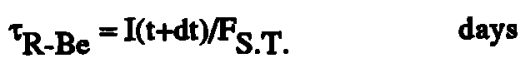

with $\mathrm{F}_{\mathrm{S} . \mathrm{T}}$. as the flux of ${ }^{7} \mathrm{Be}$ measured in sediment trap $A$ during time interval dt ( $\left.\mathrm{dpm} \mathrm{cm}^{-2} \mathrm{~d}^{-1}\right)$, and $I$ being the ${ }^{7} \mathrm{Be}$ inventory.

The ${ }^{7} \mathrm{Be}$ inventory at the end of a collection period is calculated according to (13): 
$I(t+d t)=\left\{\left(F_{a t m}-F_{S} \cdot T \cdot d t+I(t)\right\} /\left(1+\lambda_{D} \cdot d t\right) \quad d p m m^{-2}\right.$ (13) where $\mathrm{I}(\mathrm{t})$ denotes the ${ }^{7} \mathrm{Be}$ inventory at the beginning of a collection period, based on the measured $7_{\text {Be activity }}$ concentration ( ${ }^{7} \mathrm{Be}$ profile in Lake Zurich from Oct.10, 1984, Schuler et al., this issue). $\mathrm{I}(\mathrm{t}=0)$ was determined iteratively until $\mathbf{I}(\mathrm{t}=0)=\mathbf{I}\left(\mathrm{t}_{\text {end }}\right)$, using the same starting and ending month [Dominik et al., 1989].

Figure $7 a$ shows that non steady state values for $\tau_{\mathrm{Be}}$ vary seasonally and can differ substantially from the steady state or average value. The minimum residence times were found during summer (about 50 days), and the maximum values were found during the winter season (up to about 800 days). We thus postulate that the residence time of ${ }^{7} \mathrm{Be}$ is mainly a function of particle fluxes in Lake Zurich.

The overall residence time of ${ }^{7} \mathrm{Be}$ may be related to the particle flux by

$$
\tau_{B e}=\tau_{p} / f_{p}=\left(\left(C_{p} \cdot h\right) / F_{p}\right)\left(1+K_{d} \cdot C_{p}\right) /\left(K_{d} \cdot C_{p}\right) \text { days }
$$

[Santschi, 1984; Honeyman and Santschi, 1988], where $f_{P}$ represents the fraction of total nuclide associated with particle
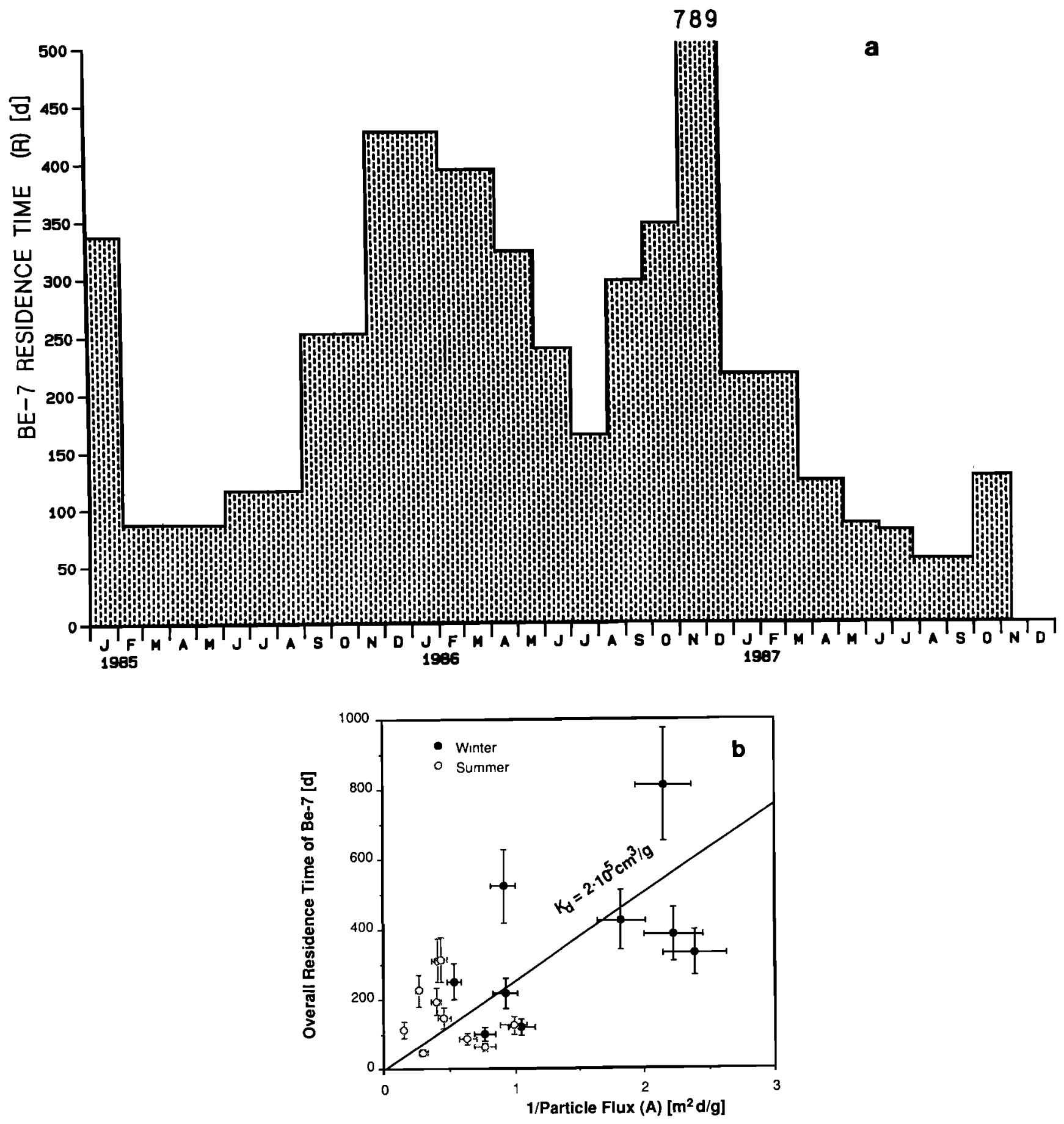

Fig. 7 (a) Non steady state residence time of ${ }^{7}$ Be plotted as a function of time. Residence time was calculated according to (12). (b) The correlation between the total residence time of ${ }^{7} \mathrm{Be}$ and the inverse particle flux in the near-surface sediment trap is also shown. The theoretical line was calculated according to (15), assuming $K_{d}=2 \times 10^{5} \mathrm{~cm}^{3} \mathrm{~g}^{-1}$. 
surfaces, $F_{p}$ is the particle flux $\left(g^{-2} \mathrm{~d}^{-1}\right), C_{p}$ denotes total particle concentration $\left(\mathrm{g} \mathrm{m}^{-3}\right), \mathrm{K}_{\mathrm{d}}$ represents the distribution coefficient $\left(\mathrm{cm}^{3} \mathrm{~g}^{-1}\right)$ and $h$ is the mean depth of Lake Zurich (= $49 \mathrm{~m}$ ). In Lake Zurich, the average particle concentration is about $0.7 \mathrm{~g} \mathrm{~m}^{-3}$ [Osman-Sigg and Stumm, 1982]. With a $\mathrm{K}_{\mathrm{d}}$ value of $2 \times 10^{5} \mathrm{~cm}^{3} \mathrm{~B}^{-1}$ [Dominik et al., 1989], we calculate $K_{d} \cdot C_{p}=0.14(<1)$, and hence, (14) may be simplified to

$$
\tau_{R-B e}=\left(h / K_{d} \cdot F_{p}\right) \quad \text { days }
$$

This indicates that the overall residence time of ${ }^{7} \mathrm{Be}, \tau_{\mathrm{R}-\mathrm{Be}}$ ' should be closely related to the residence time of settling particles in the water column. Experimental data and the calculated line $\left(K_{d}=2 \times 10^{5} \mathrm{~cm}^{3} \mathrm{~g}^{-1}\right)$ are presented in Figure 7b. It reveals that despite the scattering of the experimental data, a significant correlation of the two parameters is found, and hence, overall residence times of ${ }^{7} \mathrm{Be}$ in Lake Zurich are indeed closely related to the particle flux.

Calculation of apparent particle residence $\left(\tau_{P}\right)$ and transit times $(\Delta t)$. While average particle residence times in the water column of lakes and oceans can be long, actual transit times of particles from one depth to another are usually short, suggesting rate control by particle aggregation (both physicochemically and biologically mediated), focusing, and resuspension processes. Our data can be used to shed some light on this long-standing puzzle of particle dynamics. Apparent settling velocities of particles, $v_{p}$, can be calculated from the depth $\Delta z$ of $80 \mathrm{~m}$ between the two traps and the particle residence times, $\tau_{p}\left(\tau_{p}=d t\right)$ or transit times, $\Delta t,(\Delta t=d t)$, as follows:

$$
v_{p}=\left(z_{2}-z_{1}\right) / d t=80 m / d t \quad m d^{-1}
$$

The settling velocity, $v_{p}$, can be calculated from the changes in fluxes (e.g., attenuation or enhancements) of natural (e.g., ${ }^{10} \mathrm{Be},{ }^{7} \mathrm{Be},{ }^{210_{\mathrm{Pb}}}$ ) and Chernobyl ${ }^{137} \mathrm{Cs}$ radionuclide fluxes through the water column in the following ways:

1. In the simplest case the time scale for $\tau_{p}$ can be estimated from the application of a one-box model to particle dynamics, assuming only vertical removal, i.e.,

$$
\tau_{\mathrm{p}}={ }_{0}^{h} \int \mathrm{C}_{\mathrm{p}} \mathrm{dx} / \mathrm{F}_{\mathrm{p}} \quad \text { days }
$$

with $C_{p}$ as the particle concentration $\left(\mathrm{g} \mathrm{m}^{-3}\right), \mathrm{h}$ as the mean depth equal to volume/surface area $(=49 \mathrm{~m})$, and $F_{p}$ as the particle flux $\left(\mathrm{g} \mathrm{m}^{-2} \mathrm{~d}^{-1}\right)$.

Orders of magnitude for particle residence times in the lake, $\tau_{P}$, and settling velocities, $v_{p}$, can be estimated from combining (16) and (17), i.e., $v_{p}=F_{p} / C_{p}$. Using a value for the average particle concentration, $C_{p}$, of $0.7 \mathrm{~g} \mathrm{~m}^{-3}$, and $F_{p}=680$ $\mathrm{g} \mathrm{m}^{-2} \mathrm{yr}^{-1}$ from Schuler et al. [this issue], a value of $2.7 \mathrm{~m} \mathrm{~d}^{-1}$ can be estimated for $v_{p}$. Since this is only an order of magnitude estimate, one should not, however, expect that they should be directly comparable with the values calculated from radionuclide data.

2. For ${ }^{7} \mathrm{Be}$, such a one-dimensional model would result in an estimate for $\Delta t$, when the fluxes at the two depth levels are compared, i.e., $\left[{ }^{7} \mathrm{Be}\right.$ flux at depth $\left.\mathrm{z}_{2}\right]=\left[{ }^{7} \mathrm{Be}\right.$ flux at depth $\left.\mathrm{z}_{1}\right] \exp \left(-\lambda_{\mathrm{Be}} \Delta t\right)(18)$

If flux enhancement or depletion of ${ }^{7} \mathrm{Be}$ at depth $\mathrm{z}_{2}$ is ignored, (18) can be solved for the apparent particle transit time, $\Delta \mathrm{t}$. Values of $\mathrm{vp}$ calculated from ${ }^{7} \mathrm{Be}$ fluxes according to (18) are, however, not always determinable, as $\Delta t$ can become undetermined or highly variable when ${ }^{7} \mathrm{Be}$ fluxes at the two depths become similar within the errors of the measurements. Values calculated according to (18) average $10 \mathrm{~m} \mathrm{~d}^{-1}$. The variations in $\Delta t$ are, to a large extent, a consequence of additional lateral boundary inputs which have been ignored in the derivation.

3. Since the assumption of constant vertical flux is, in the light of our data, not justified, we have to include a lateral transport term for the calculation of $\Delta t$. One way to accomplish this is to use two nuclides which are carried on the same carrier or host phase. Both $\mathrm{Be}$ and $\mathrm{Pb}$ nuclides are strongly adsorbed onto $\mathrm{Fe}$ and $\mathrm{Mn}$ oxide phases. The evidence for $\mathrm{Be}$ is reviewed by Hawley et al. [1986]; for $\mathrm{Pb}$, the evidence comes from significant correlations of $\mathrm{Pb}$ fluxes with those of $\mathrm{Fe}$ [Sigg et al., 1987; Benoit and Hemond, 1986, 1990] and from associations of $\mathrm{Pb}$ with $\mathrm{Mn}$ in sediments [Dominik et al., 1989]. Cs nuclides are found strongly sorbed onto clay minerals, particularly illites [e.g., Duursma and Bewers, 1986]. It is likely then that fine, metal oxide- and clay-rich particles, which originate from a sediment-water interface where they had become diagenetically enriched in Fe or Mn [e.g., Benoit and Hemond, 1990], are transported laterally to our lower sediment traps (B). An adsorbed short-lived nuclide (e.g., ${ }^{7} \mathrm{Be}$ ) would partially decay during the lateral transport time, while a longerlived one, $\mathrm{N}$, (e.g., ${ }^{10} \mathrm{Be},{ }^{210} \mathrm{~Pb},{ }^{137} \mathrm{Cs}$ ) would not. A ratio of the flux equations at water depth $\mathrm{z}_{1}$ and $\mathrm{z}_{2}$ for the two nuclides will result in an improved calculation of $\Delta t$, i.e.,

$\left[\left\{{ }^{7} \mathrm{Be}\right] /(\mathrm{N}\}\right.$ at $\left.\mathrm{z}_{2}\right]=\left[{ }^{7} \mathrm{Be}\right\} /\{\mathrm{N}]$ at $\left.\mathrm{z}_{1}\right] \exp \left(-\left(\lambda_{7} \mathrm{Be}^{-\lambda_{\mathrm{N}}}\right) \Delta \mathrm{t}\right)(19 a)$

with the curly braces denoting concentrations on sinking particles and $\lambda_{7 \mathrm{Be}}=0.013 \mathrm{~d}^{-1}$.

Equation (19a) can be solved for the apparent particle transit time, $\Delta t$, by assuming similar particle pathways and focusing for ${ }^{7} \mathrm{Be}$ as for the nuclide $\mathrm{N}$ (i.e., for ${ }^{10} \mathrm{Be}, 210_{\mathrm{Pb}},{ }^{137} \mathrm{Cs}$ ), and because of $\lambda_{\mathrm{N}} \ll \lambda_{7 \mathrm{Be}}\left(\lambda_{10} \mathrm{Be}=1.3 \times 10^{-9} \mathrm{~d}^{-1}, \lambda_{137} \mathrm{Cs}=6.33 \times\right.$ $10^{-5} \mathrm{~d}^{-1}$ and $\lambda_{210 \mathrm{~Pb}}=8.48 \times 10^{-5} \mathrm{~d}^{-1}$ ), as follows:

$\Delta t=\left(1 / A_{7}{ }_{\mathrm{Be}}\right) \cdot \ln \left(\left[\left\{^{7} \mathrm{Be}\right\} /\{\mathrm{N}]\right.\right.$ at $\mathrm{z}_{1} \mathrm{~V}\left[\mathrm{l}^{7} \mathrm{Be}\right\} /[\mathrm{N}\}$ at $\left.\left.\mathrm{z}_{2}\right]\right)$ days(19b)

Apparent particle settling velocities, calculated from all available particle and radionuclide data, are summarized in Table 3 and presented in Figures $8 a$ and $8 b$. Nuclide ratios used in (19b) can be averaged for each season (Table 3 ). In either case, $v_{p}$ calculated from combining $(19 \mathrm{~b})$ and $(16)$ are lowest, i.e., $2-4 \mathrm{~m} \mathrm{~d}^{-1}$, using either ${ }^{10} \mathrm{Be},{ }^{210} \mathrm{~Pb}$, or ${ }^{137} \mathrm{Cs}$ data to correct for enhancement of lateral transport. As the ratio of ${ }^{10} \mathrm{Be} / 7^{7} \mathrm{Be}$ is not affected by chemical processes, we consider the estimate of $2.3 \pm 0.7 \mathrm{~m} \mathrm{~d}^{-1}$ as the most reliable one of the three.

While (16)-(19) likely result in the best estimate for an effective settling or transfer velocity of nuclide-bearing particles, actual transit times for particles settling from $50 \mathrm{~m}$ to $130 \mathrm{~m}$ depth can be considerably faster. Indeed, the 


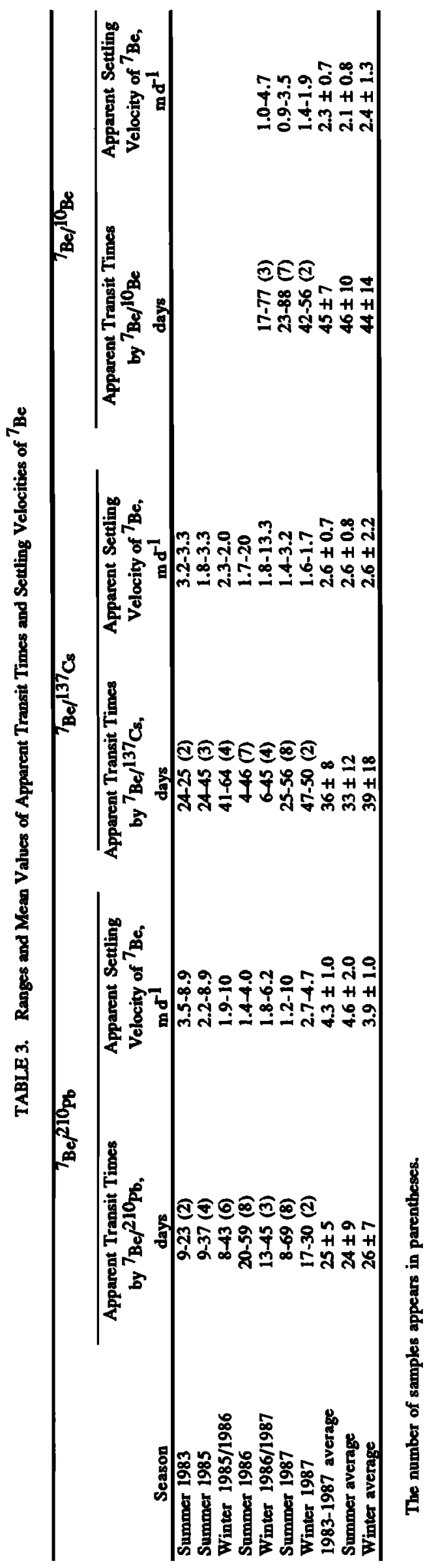

measurements of the flux of Chemobyl ${ }^{137} \mathrm{Cs}$ in these traps (and of the other radionuclides found in this fallout) allowed the estimation of an apparent settling velocity of $16-18 \mathrm{~m} \mathrm{~d}^{-1}$. Such an estimate is possible because the sediment traps were changed immediately before the fallout arrived. The Chemobyl 137 Cs pulse was caught in the sediment traps which were changed on April 29, 1986, and exposed for 21 days $\left(t_{1}\right)$. Actual transit times of Chemobyl fallout containing particles $(\Delta t)$ can be calculated from a knowledge of the radionuclide (e.g., $\left.{ }^{137} \mathrm{Cs}\right)$ fluxes at a depth of $50 \mathrm{~m}\left(=\mathrm{F}_{\mathrm{A}}\right)$ and $130 \mathrm{~m}\left(=\mathrm{F}_{\mathrm{B}}\right)$ and by taking into account the fact that the peak fallout occurred on May 1, 1986 [Santschi et al., 1988], as follows.

The total fallout was contained almost entirely in these traps exposed for 21 days. The radionuclide inventory during this exposure time is

$$
\int_{0}^{t} F(t) d t
$$

Thus, the inventory ratio is

$\int_{0}^{\infty} F_{B}\left(t_{2}\right) d t \int_{0}^{1} F_{A}\left(t_{1}\right) d t=0.75$

as was measured for ${ }^{137} \mathrm{Cs},{ }^{134} \mathrm{Cs},{ }^{103} \mathrm{Ru}$ etc. With $\mathrm{t}_{1}=(21$ days $-d t), t_{2}=\left(t_{1}-\Delta t\right)$, the time for the fallout to reach $50 \mathrm{~m}$ depth, dt, can be estimated by trial and error.

The time $\Delta t$ can be calculated, for cases of constant $F_{A}$ (i.e., $F=u$ ), or for linearly (i.e., $F=-v t+u$ ) or exponentially decreasing (i.e., $F=\exp (-\mathrm{ct})$ ) fluxes $F_{A}$. Assuming that the initial rate of decrease is similar to the decreasing fallout flux in sediment trap $A$ during the spring and summer months of 1986 [Schuler et al, this issue, Figure 2d], one obtains a value for $c=0.014 \mathrm{~d}^{-1}$; exact $\mathrm{u}$ and $\mathrm{v}$ values are irrelevant here, as they drop out of the ratio of the two integrals. Using the values given above and the measured ratios of the respective flux integrals of 0.75 , we calculate 4.5 to 5 days for the transit time between 50 and $130 \mathrm{~m}$ depth, independent of the assumptions used for the $F_{A}$ function. The value of $v_{p}$ then becomes 16-18 $\mathrm{m} \mathrm{d}^{\mathbf{- 1}}$. This value changes very little, even after correcting it for the time it took to settle from 0 to $50 \mathrm{~m}$ depth. Incidentally, this value of $17 \mathrm{~m} \mathrm{~d}^{-1}$ is about 3 orders of magnitude faster than the settling velocity of the radionuclide-containing aerosols of $0.7 \mathrm{~mm}$ diameter (taken from Jost et al. [1986]). This suggests that these aerosols either coagulate with calcite precipitating out of the lake during that time, or that the radionuclides leach off the aerosols and quickly readsorb onto larger, fastersettling particles or aggregates [Santschi et al., 1987]. Settling velocities of this magnitude are the same as those of calcite crystals of $15-20 \mathrm{~mm}$ diameter, of a density of $2.5 \mathrm{~g}$ $\mathrm{cm}^{-3}$, and at a temperature of $14^{\circ} \mathrm{C}$, as observed on settling material of lakes in northern Switzerland [Sturm et al., 1982].

Although these large particles settle fast $\left(v_{P}=16-18 \mathrm{~m}\right.$ $\mathrm{d}^{-1}$ ), the overall scavenging process is dominated by slow particle transport processes $\left(v_{P}=2.3 \mathrm{~m} \mathrm{~d}^{-1}\right.$ ). As will be shown later, there appears to be some loss of ${ }^{210} \mathrm{~Pb}$ (and ${ }^{137} \mathrm{Cs}$ ) from the underlying sediments, thus possibly supporting some recycling of $210 \mathrm{~Pb}$ (and ${ }^{137} \mathrm{Cs}$ ) from the anoxic bottom waters into the bottom trap. Such recycling could weaken or invalidate our suggested settling model. However, the following observations would argue in favor of our settling model.

1. Nuclides with widely differing input functions, half-lifes, 

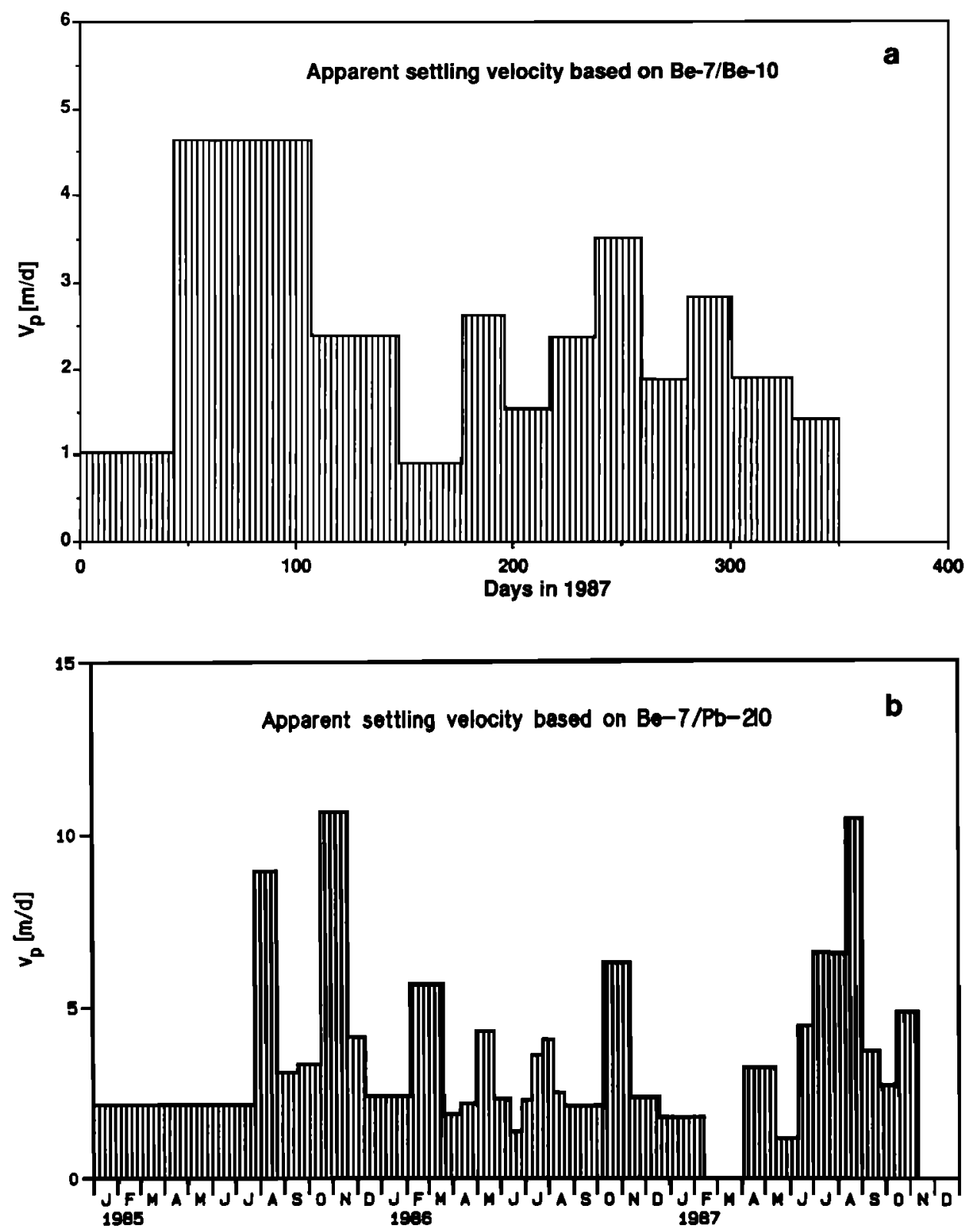

Pig. 8 Apparent settling $\left(v_{\mathrm{p}}\right)$ velocity based on $(a){ }^{7} \mathrm{Be} /{ }^{10} \mathrm{Be}$ ratios measured in the sediment traps in 1987 and (b) ${ }^{7} \mathrm{Be} /{ }^{210} \mathrm{~Pb}$ ratios measured in the sediment traps between 1983 and 1987 . The settling velocity, $\mathrm{v}_{\mathrm{P}}, \mathrm{was}$ calculated according to (16) and (19) and plotted as a function of time.

chemical properties, and susceptibilities to benthic remobilization (i.e., $\mathrm{Pb}, \mathrm{Cs}$, and $\mathrm{Be}$ ) all give the same apparent settling velocity of $2-4 \mathrm{~m} \mathrm{~d}^{-1}$. This also argues for a better precision and accuracy of our radionuclide-derived settling velocities than of those derived by taking a simple ratio of particle flux to particle standing crop. Furthermore, the agreement of the apparent settling velocity calculated with different nuclides would also argue against a significant bias by mixing variable amounts of vertically settling "virgin" with laterally derived older particles in the near-bottom waters.

2. Our model-derived apparent overall settling time of 20 to $\mathbf{4 0}$ days (rather than $4-5$ days) to settle from $50 \mathrm{~m}$ to $130 \mathrm{~m}$ depth is in agreement with the observation of a delayed overall transfer of Chernobyl ${ }^{137} \mathrm{Cs}$ from the epilimnion to the hypolimnion during the summer 1986 . The flux enhancement at $130 \mathrm{~m}$ water depth over that at $50 \mathrm{~m}$ of the pulsed input of ${ }^{137} \mathrm{Cs}$ in early May 1986 [Santschi et al., 1990] was observed with a delay of 1-2 months.

3. The near-bottom particle flux increased also at a shallower station further to the east that was occupied in 1983/1984 and which had no anoxic bottom waters (P. H. Santschi, unpublished results, 1985), suggesting that the flux enhancement is not directly related to anoxic conditions.

Adsorption/coagulation process $\left(\tau_{C}\right)$. From the apparent overall settling velocity $\left(v_{P}=2.3 \pm 0.7 \mathrm{~m} \mathrm{~d}^{-1}\right.$; Table 3$)$ and the mean depth $(=49 \mathrm{~m})$, the overall particle residence time, $\tau_{\mathbf{P}}$, in a steady state system can be calculated to be $21 \pm 6$ days. The overall removal residence time of ${ }^{7} \mathrm{Be}, \tau_{\mathrm{R}-\mathrm{Be}}$, given in Table 2 is $176 \pm 62$ days. Using (6), a range of 60-185 days (average: 
120 days) can be calculated for $\tau_{C}$, the characteristic time for both adsorption and coagulation combined. For ${ }^{210} \mathrm{~Pb}$, the characteristic time $\tau_{C}$ ranges from 3 to 31 days (average: 17 days).

The rate constant for adsorption and coagulation may also be determined from coagulation models. According to Honeyman and Santschi [1989], $\lambda_{C}\left(=1 / \tau_{C}\right)$ can be expressed as

$$
\lambda_{\mathbf{C}}=\mathbf{k}_{\mathbf{f}} \mathbf{f}_{\mathbf{P}}
$$

Using the semiempirical model of Farley and Morel [1986] for a typical particle concentration, $C_{p}$, of $0.7 \mathrm{mg} \mathrm{L}^{-1}$, the first-order rate constant, $\mathbf{k}_{\mathbf{f}}$, with respect to coagulation and sedimentation can be calculated as $k_{f}=0.1 \mathrm{~d}^{-1}$. Since adsorption occurs within milliseconds to seconds, this is the rate constant for adsorption plus coagulation [Honeyman and Santschi, 1989]. The fraction of total nuclide associated with particle surfaces, $f_{p}$, is given by

$$
f_{P}=K_{d} \cdot C_{P} /\left(1+K_{d} \cdot C_{P}\right)
$$

or

$$
\mathbf{f}_{\mathbf{P}}=\tau_{\mathbf{P}} / \tau_{\mathbf{R}}
$$

Using typical values of $K_{d}=2 \times 10^{5} \mathrm{~cm}^{3} \mathrm{~g}^{-1}, \mathrm{C}_{\mathrm{P}}=0.7 \mathrm{mg}$ $L^{-1}, \tau_{P}=21$ days, and $\tau_{R}=176$ days, values for $f_{P}$ range from 0.12 to 0.15 (as calculated from (22) and (23)), which are also in agreement with those measured by Dominik et al. [1989]. Values for $\tau_{C}\left(=1 / \lambda_{C}\right)$, estimated from (21), are then about 60 to 80 days, in agreement with those calculated from (6), which range from 63 to 90 days.

Both ways of calculating the characteristic time ${ }^{\tau_{C}}$ indicate that the overall removal process of atmospherically deposited ${ }^{7} \mathrm{Be}$ from the water column to the sediments is mainly controlled by the adsorption/coagulation step and not by the rate of particle settling. In the case of fast adsorption/coagulation processes (e.g., $k_{f}=0.1 \mathrm{~d}^{-1}$, i.e., $\tau_{\text {coag }} \approx 10$ days), $\tau_{C}$ represents the characteristic time it takes for ${ }^{7} \mathrm{Be}$ ion to find a reactive particle surface. Because of the higher affinity of ${ }^{210} \mathrm{~Pb}$ for particle surfaces, the characteristic time $\tau_{C}$ for adsorption/coagulation of ${ }^{210} \mathrm{~Pb}$ is reduced, and hence, the value of $\tau_{C}$ becomes of the same magnitude as the residence time with respect to particle settling, ${ }^{\tau} \mathbf{P}$

To explain this novel phenomenon of slow overall apparent settling velocities and fast transit times, coupled with the observations of periodic radionuclide and particle flux enhancements with depth during the summer stagnation period, we propose the following hypothesis: density currents, produced by slightly heavier water originating from the flux of $\mathrm{Ca}^{2+}, \mathrm{HCO}_{3}{ }^{-}, \mathrm{Mn}^{2+}, \mathrm{H}_{4} \mathrm{SiO}_{4}$, or other ions diffusing out of lateral boundary sediments, or from an unconsolidated layer of flocculent particles overlying these sediments, could deflect settling particles (i.e., "virgin" particles) from permanently becoming part of the sedimentary record and sweep them into the deeper part of the lake, thus effectively focusing finegrained particles to deeper-lying sediments during the stratification period. The pulsed and cyclid nature of the fluxes could result from the time needed to build up enough density contrast to initiate the lateral movement. The resulting current would, of course, destroy, for a short period of time, the density stratification which is able to initiate boundary currents. This hypothesis is supported by an observed inverse correlation of the occurrence and magnitude of radionuclide and particle flux maxima events at $130 \mathrm{~m}$ depth with wind speed measured on the shores of Lake Zurich (not shown). These radionuclide flux events at $130 \mathrm{~m}$ depth can be more than twice their respective values at $50 \mathrm{~m}$ depth. The inverse correlation would suggest that quiet lake conditions are needed to produce such a phenomenon. Quiet conditions favor thicker benthic diffusive sublayers [e.g., Santschi et al., 1983]. Brandl [1987] has measured pore water profiles of methane and $\mathrm{Mn}^{2+}$ in Lake Zurich, using diffusion chambers deployed by submersibles, which show large concentration gradients extending $5-10 \mathrm{~cm}$ into the overlying water column. This would effectively allow the benthic flux of the main species diffusing out of the sediments, $\mathrm{Mn}^{2+}, \mathrm{Ca}^{2+}, \mathrm{HCO}_{3}^{-}$, and $\mathrm{H}_{4} \mathrm{SiO}_{4}$, to enrich this stagnant boundary layer, making it slightly heavier than the overlying water and producing slow currents near sloping sediments. In addition, any unconsolidated, flocculent particles overlying the sediments would also significantly enhance the density of this layer. Indeed, measurements of current velocities in a number of Swiss Lakes indicate low current speeds of $\leq 2 \mathrm{~cm} \mathrm{~s} \mathbf{s}^{-1}$ above sediments during stratification periods [Lemmin and Imboden, 1987], certainly not enough to resuspend consolidated sediments. Slow currents driven by thermally induced small density enhancements have been described by Likens [1965], applying $\mathrm{Na}$ isotopic tracer methods in an ice-covered lake. However, radionuclides only provide suggestive evidence here. The evidence at hand does not prove that such a mechanism is actually occurring. Further experiments using physical (i.e., tracer release near the sediment-water interface), geochemical (i.e., pore water gradient measurements using diffusion chambers) and sedimentological (i.e., by two-dimensional arrays of sediment traps) methods are needed to prove such a hypothetical mechanism.

\section{SUMMARY AND CONCLUSIONS}

Significant correlations of ${ }^{7} \mathrm{Be},{ }^{10} \mathrm{Be},{ }^{210} \mathrm{~Pb}$, and ${ }^{137} \mathrm{Cs}$ radionuclide fluxes in Lake Zurich were observed (1) between two radioisotope pairs in sediment traps deployed at $50 \mathrm{~m}$ and $130 \mathrm{~m}$ depth, (2) between a radionuclide and the particle flux, and (3) between radiotracer fluxes collected from the atmosphere and in sediment traps at $50 \mathrm{~m}$ depth. These correlations can be explained by distinguishing two particle flux control regimes. Nuclide removal in winter is controlled by particle flux (i.e., nuclide fluxes correlate tightly with particle flux), while in the summer, nuclide removal is usually controlled by input fluxes which are more variable, and most incoming nuclides are rapidly transferred to the sediments (i.e., nuclide fluxes at $50 \mathrm{~m}$ depth significantly correlate with atmospheric fluxes).

The determination of nuclide fluxes and concentration profiles led to the calculation of nuclide removal residence times. Nuclide removal residence times vary substantially from one nuclide to another, i.e., ranging from about 1 month for ${ }^{210} \mathrm{~Pb}$, to 6 months for ${ }^{7} \mathrm{Be}$, and to $10-26$ months for ${ }^{210} \mathrm{Po}$. Average steady state residence times of ${ }^{210} \mathrm{~Pb}$ (and ${ }^{210} \mathrm{Po}$ ) are 
similar in winter and in summer, despite 3-6 times higher particle fluxes in summer. It is likely that the flux enhancement due to $\mathrm{CaCO}_{3}$ precipitation in the summer is not accompanied by an enhanced removal of ${ }^{10} \mathrm{Be},{ }^{7} \mathrm{Be},{ }^{210} \mathrm{~Pb}$, and ${ }^{137} \mathrm{Cs}$ due to the low adsorption and scavenging efficiency of $\mathrm{CaCO}_{3}$ for these radionuclides.

Apparent settling velocities of particles were calculated from nuclide fluxes measured at two different depths. Particle and nuclide focusing to the deepest part of Lake Zurich decreases the apparent overall settling velocity of nuclidebearing particles from a value for the transit velocity of about $17 \mathrm{~m} \mathrm{~d}^{-1}$ to an effective settling velocity of about $2-4 \mathrm{~m} \mathrm{~d}^{-1}$. This latter settling velocity is an average over fast-settling particles from the vertical component of the flux and the slowly moving particles of the lateral flux component. The higher value was derived from the attenuation of the Chemobyl ${ }^{137}$ Cs flux through the water column in May 1986, and the lower estimate of effective settling velocity was derived from the use of ${ }^{7} \mathrm{Be} /{ }^{10} \mathrm{Be},{ }^{7} \mathrm{Be} /{ }^{210} \mathrm{~Pb}$, and ${ }^{7} \mathrm{Be} /{ }^{137} \mathrm{Cs}$ ratios as chronometers for the effective velocity of the sinking particles settling from trap $A$ at $50 \mathrm{~m}$ depth to trap $B$ at $130 \mathrm{~m}$ depth.

Thus, it appears that aggregation processes of particles as well as a focusing process, originating near the horizontal boundaries of the lake, affect the transit of particles from the surface to the bottom of the lake. It is hypothesized that density currents, originating from back diffusion of $\mathrm{Mn}^{2+}$, $\mathrm{Ca}^{2+}$, and $\mathrm{HCO}_{3}{ }^{-}$out of boundary sediments, or from a flocculent layer of unconsolidated, freshly deposited, and fine particles at horizontal boundaries, are responsible for a flux enhancement of radionuclides and particles at greater depth in the lake during the stagnation period. This novel observation of radionuclide and sediment focusing during the stagnation period of a lake is different from previously described focusing and resuspension effects in lakes, which are usually observed due to wind-enhanced current velocities during lake tumover.

Acknowledgments. The manuscript has benefited from the critical comments on an earlier draft by D. Imboden (EAWAG/ETH Zurich), $M$. Baskaran and G. Benoit (TAMUG), and J. Dominik (Universite de Geneve). Reviews by W. Ela, S. Moran, G. Redden, and two anonymous reviewers are kindly acknowledged. This work was in part supported by the EAWAG's teaching and research funds, by the Swiss National Science Foundation, and at Texas A\&M University, Galveston, by the Texas Advanced Research Program (grant 4697) and the Texas Institute of Oceanography.

\section{REFERENCES}

Barnes, R. S., P. B. Birch, D. E. Spyridokis, and W. R. Schell, Changes in the sedimentation histories of lakes using lead-210 as a tracer of sinking particulate matter, in Isotope Hydrology 1978, vol. 2, pp. 875-898, Intemational Atomic Energy Agency, Vienna 1979.

Benoit, G., and $\mathrm{H}$. Hemond, A biogeochemical mass balance of ${ }^{210_{\mathrm{Po}}}$ and $210 \mathrm{~Pb}$ in an oligotrophic lake with seasonally anoxic hypolimnion, Geochim. Cosmochim. Acta, 51, 1445-1456, 1986.

Benoit, $\mathrm{G}$., and $\mathrm{H}$. Hemond, ${ }^{210} \mathrm{Po}$ and ${ }^{210} \mathrm{~Pb}$ remobilization from the lake sediments in relation to iron and manganese cycling, Environ. Sci. Technol., 24, 1224 - 1234, 1990.

Brandl, H., Mikrobielle Prozesse unter Oxidationsmittel-limitierten Bedingungen an der Sediment-Wasser-Uebergangszone in Seen, Ph.D. thesis, 201 pp., Univ. of Zurich, Zurich, Switzerland, 1987.

Dominik, J., C. Schuler, and P. H. Santschi, Residence times of ${ }^{234} \mathrm{Th}$ and ${ }^{\mathrm{Be}}$ in Lake Geneva, Earth Planet. Sci. Lett., 93, 345-358, 1989.
Durham, R. W., and S. I. Joshi, Recent sedimentation rates, $210 \mathrm{~Pb}$ fluxes and particle settling velocities in Lake Huron, Laurentian Great Lakes, Chem. Geol., 31, 53-66, 1980.

Duurama, E. K., and J. M. Bewers, Application of $K_{d}$ in marine geochemistry and environmental assessment, in Application of Distribution Coefficients to Radiological Assessment Models edited by T. H. Sibley and C. Myttenaere, Pp. 138-165, Elecvier, New York, 1986.

Farley, K. J., and F. M. M. Morel, Role of coagulation in the kinetics of sedimentation, Environ. Sci. Technol., 20, 187-195, 1986.

Hawley, N., J. A. Robbins, and B. J. Eadie, The partitioning of 7 beryllium in fresh water, Geochim. Cosmochim. Acta, 50, 1127 $1131,1986$.

Honeyman, B. D., and P. H. Santschi, Metals in aquatic systems, Environ. Sci. Technol., 22, 862-871, 1988.

Honeyman, B. D., and P. H. Santschi, A Brownian-pumping model for trace metal scavenging: Evidence from Th isotopes, J. Mar. Res., 47, 951-992, 1989.

Jost, D. T., H. W. Gaeggeler, U. Baltensperger, B. Zinder, and P. Haller, Chernobyl fallout in size-fractionated aerosol, Nature, 324, 22-23, 1986.

Lemmin, U., and D. M. Imboden, Dynamics of bottom currents in a small lake, Limnol. Oceanogr., 32, 62-75, 1987.

Likens, G. E., Vertical water motions in a small ice-covered lake, $J$. Geophys. Res., 70, 2333-2344, 1965.

Osman-Sigg, G. K., and W. Stumm, Partikelgrössenverteilung und naturliche Koagulation im Zürichsee, Schweiz. Z. Hydrol., 44/2, 405-422, 1982.

Santschi, P. H., Particle flux and trace metal residence times in natural waters, Limnol. Oceanogr., 29, 1100-1108, 1984.

Santschi, P. H., Use of radionuclides in the study of contaminant cycling processes, Hydrobiologia, 176/177, 307-320, 1989.

Santschi, P. H., D. Adler, M. Amdurer, Y. H. Li, and J. J. Bell, Thorium isotopes as anslogous for "particle-reactive" pollutants in coastal marine environments, Earth Planet. Sci. Lett., 47, 327-335, 1980.

Santachi, P. H., P. Bower, U. P. Nyffeler, A. Azevedo, and W. S. Broecker, Estimates of the resistance to chemical transport posed by the deep-sea boundary layer, Limnol. Oceanogr., 28, 899-912, 1983.

Santschi, P. H., C. Schuler, and M. Sturm, Natural and Chernobyl radionuclides as tracers of particle settling and resuspension in Lake Zurich, Switzerland, Terra Cognita, 7(2-3), 185, 1987.

Santschi, P. H., S. Bollhalder, K. Farrenkothen, A. Lueck, S. Zingg, and $M$. Sturm, Chemobyl radionuclides in the environment: Tracers for the tight coupling of atmospheric, terrestrial and aquatic geochemical processes, Environ. Sci. Technol., 22, 510-516, 1988.

Santschi, P. H., S. Bollhalder, S. Zingg, A. Lueck, and K. Farrenkothen, The self-cleaning capacity of surface waters after radioactive fallout: Evidence from European waters after Chernobyl, 1986-1988, Environ. Sci. Technol., 24, 519-527, 1990.

Schell, W. R., Sedimentation rates and mean residence times of atable $\mathrm{Pb}$ and ${ }^{210} \mathrm{~Pb}$ in Lake Washington, Puget Sound estuaries and a coastal region, USAEC Rep. RLO-2225-T14-6, Radiat. Ecol. Lab., Univ. of Wash., Coll. of Fish., Seattle, 1974.

Schuler, C., B. Wieland, P. H. Santschi, M. Sturm, A. Lueck, K. Farrenkothen, S. Bollhalder, J. Beer, G. Bonani, H. J. Hofmann, M. Suter, and W. Wolfli, A multitracer study of radionuclides in Lake Zurich, Switzerland, 1, Comparison of atmospheric and sedimentary fluxes of ${ }^{7} \mathrm{Be},{ }^{10} \mathrm{Be},{ }^{210} \mathrm{~Pb},{ }^{210} \mathrm{Po}$, and ${ }^{137} \mathrm{Cs}$, J. Geophys. Res., this issue.

Sigg, L., M. Sturm, and D. Kistler, Vertical transport of heavy metals by settling particles in Lake Zurich, Limnol. Oceanogr., 32, 112$130,1987$.

Stiller, M., and D. M. Imboden, ${ }^{210} \mathrm{~Pb}$ in Lake Kinneret waters and sediments: Residence times and fluxes, in Sediment and Water Interactions, edited by P. G. Sly, Pp. 501-511, Springer-Verlag, New York, 1986.

Sturm, M., U. Zeh, J. Mueller, L. Sigg, and H.-H. Stabel, Schwebstoffuntersuchungen im Bodensee mit IntervallSedimentationsfallen, Eclogae Geol. Helv., 75, 579-588, 1982.

Talbot, R. W., and A. W. Andren, Seasonal variations of $210 \mathrm{~Pb}$ and 210 Po concentrations in an oligotrophic lake, Geochim. Cosmochim. Acta, 48, 2053-2063, 1984. 
Wan, G. J., P. H. Santschi, M. Sturm, K. Farrenkothen, A. Lueck, B.

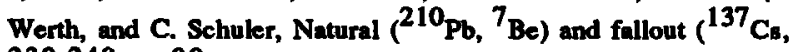
$239,240_{\mathrm{Pu}},{ }^{90} \mathrm{Sr}$ ) radionuclides as geochemical tracers of sedimentation in Groifensee, Switzerland, Chem. Geol., 63, 181196, 1987.

J. Beer, Swiss Federal Institute of Water Resources and Water Pollution Control (Eidgenössische Anstalt für Wasser, Abwaeser und Gewbisserschutz, EAWAG), 8600 Dubendorf, Switzerland.
P.H. Santschi, Department of Marine Sciences, Texas A \& $M$ University, Galveston, TX 77553.

E. Wieland, Department of Civil Engineering, Stanford University, Stanford, CA $94305-4002$.

(Received June 21, 1990; revised May 30, 1991; accepted December 28, 1990.) 